\title{
Bread Wastage in Iran during 2001-2021: A Systematic Review
}

\author{
Ramesh Allipour Birgani ${ }^{1}$, Ali kianirad ${ }^{2}$, Amirhossain Takian $^{3}$, Hamed Pouraram $^{1}$ * \\ 1. School of Nutritional Sciences \&Dietetics, Tehran University of Medical Sciences, Tehran, Iran \\ 2. Agricultural Planning, Economic and Rural Development Researches Institute. Agricultural Deputy, Tehran, Iran \\ 3. School of Public Health, Tehran University of Medical Sciences, Tehran, Iran
}

Received: 17 September 2021

Accepted for publication: 7 December 2021

[EPub a head of print-13 December 2021]

Payesh: 2021; 20 (6): 687- 702

\begin{abstract}
Introduction: Bread as a staple food, especially wheat bread is a main source of energy consumption in large number of population in the globe as well as Iran. Some researches stated that the amount of bread wastage is about $30 \%$ in Iran. there isn't any general research with comprehensive picture of bread wastage in Iran.

Objective: It is necessary to design a systematic review study to bring holistic figure on substantial reason of bread waste for policy makers to improve the Iranian food security.

Method: systematic review was performed with key words of bread wastage, quality, type, traditional, industrial production, Iran in the international PubMed, Google Scholar) and Iranian data base SID, CIVILICA 'GANJ in 2021. The inclusion criteria were: study the reason and results only for bread wastage, the relevance of the articles with the title, the language of articles English or Persian, availability the full text of articles. sensitivity analysis was employed.

Results: out of 441 articles ,25 articles (1 in English and 24 in Persian language) get good quality to extract the data during (2001-2021) years printed in scientific local and international sources. $48 \%$ of studies conducted in laboratories and $52 \%$ was performed in community at both consumer's part and bakeries or Industrial producers. The most proportion of bread waste in all types was seen in bakeries that received subsides to buy flour. community investigation demonstrated the considerable effect of consumers' knowledge in transport, preserve and bread consumption on diminish the amount of bread waste.

Conclusion: According to the consumer's behavior the willingness to pay shows upward rate for high quality breads which is the principal reason for decreasing bread waste. These consequences primarily observed in private bakeries. consequences elucidate the necessary of reform by policymakers in bread production and consumption sectors in Iran.
\end{abstract}

Keywords: bread wastage, quality, type, traditional, industrial production, Iran.

\footnotetext{
* Corresponding author: School of Nutritional Sciences \&Dietetics, Tehran University of Medical Sciences, Tehran, Iran

E-mail: h-pouraram@tums.ac.ir
} 


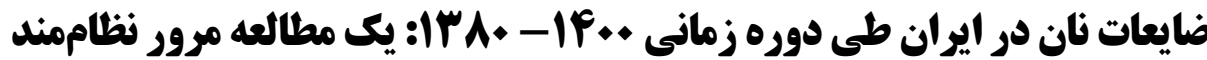

\author{
رامش عالى يور بير كانى'، على كيانى راد'، امير حسين تكيان"، حامد بور آرام'* \\ 1. دانشكده تغذيه و رزيمشناسى، دانشكاه علوم يزشكى تهران، تهران، ايران

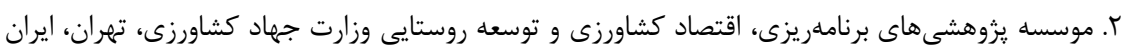

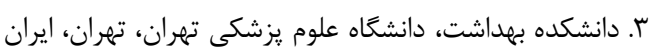

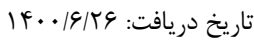

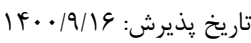

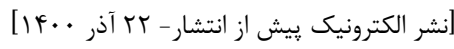

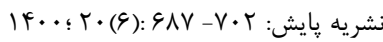

جـكيده

مقدمه: نان بخصوص نان گَندم بعنوان تامين كننده اصلى انرزى در بسيارى از كشورهاى جهان از جمله ايران به شمار مىرود. در عين حال بررسىها بيانكر

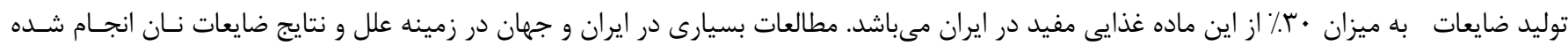

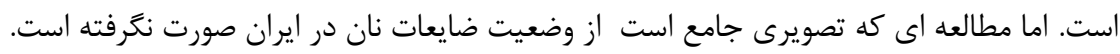

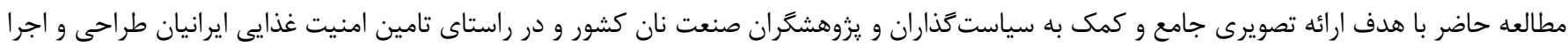
گرديد.

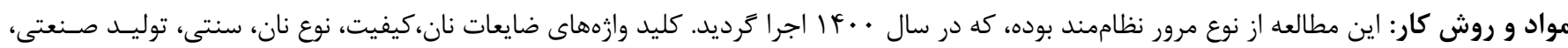

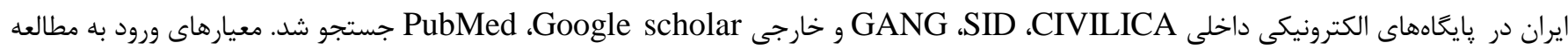

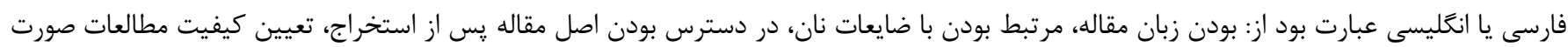

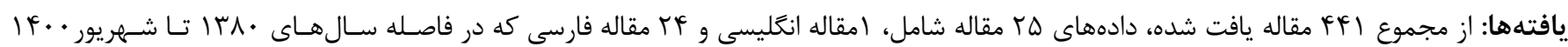

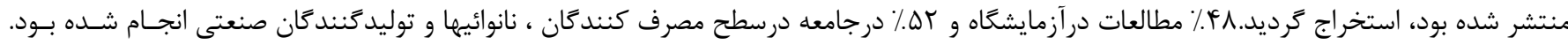

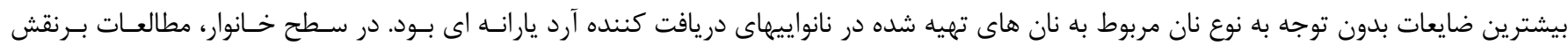

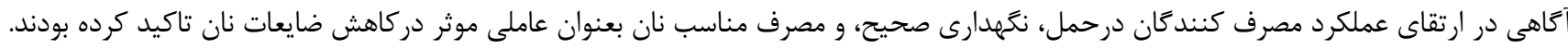

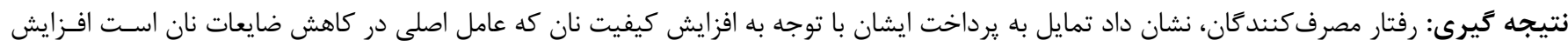

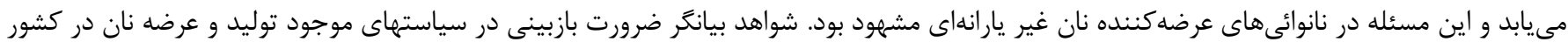


در تشخيص سازوكاربياتى نان و روشهاى به تاخير انداختن آن موثر واقع شود. با توجه به اينكه از بر همكنش شيميايى و مولكولى اجزاء

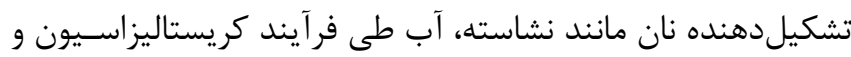

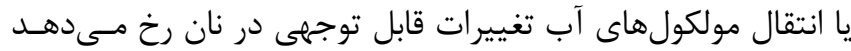
كه مىتواند در كيفيت نان، عطر و طعم آن موثر باشد، لذا به منظور

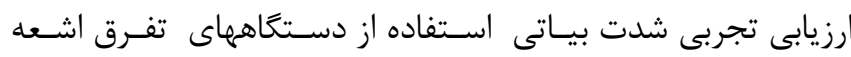

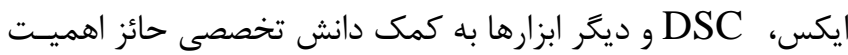

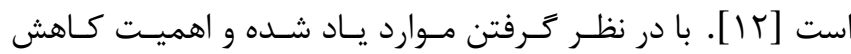

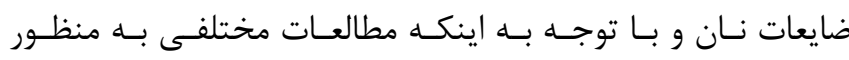
اندازهيرى شدت بياتى نان در ايران انجام شده است كه هركدام به به بهات

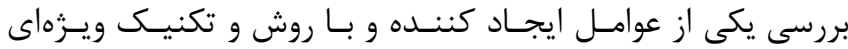

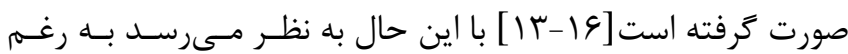

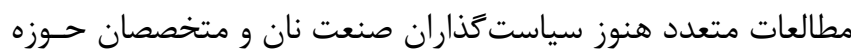
غذا و تغديه تصوير كاملى از وضعيت بررسىهاى انجام شده با هـــف

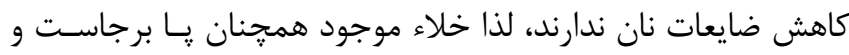

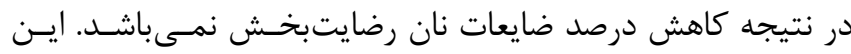

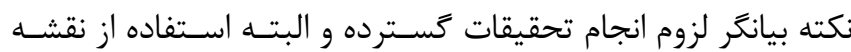
راهى قابل اطمينان است. بدين منظور مطالعه مرور نظاممند حاضـر

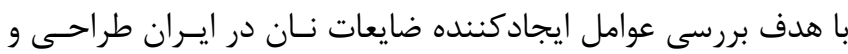

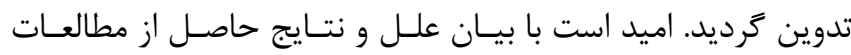

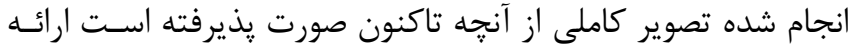

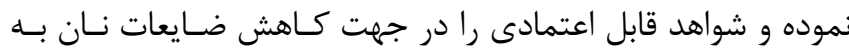
محققين و سياست كذاران حوزه غـذا و تغذيـه و صـنعت نـان ارائسه

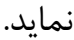

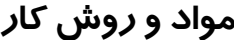

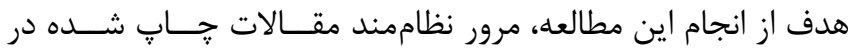

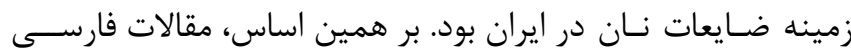
زبان קاب شده در مجلات علمى ـ يزوهشى داخل كشـور و مقـالات

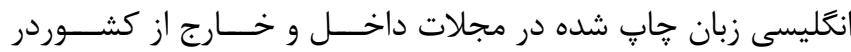
زمينه ضايعات نان در ايران مـورد جستجو قرار كَرفتند.

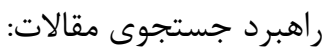
كليد وازها: ا - كليد وازههاى مورد نظر عبارت بودند از: وازّه ضايعات نان، كيفيت، نوع نان، سنتى، توليد صنعتى، ايران كه بر اسـاس ايـن إنـ

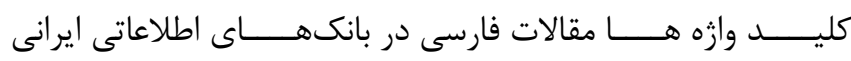

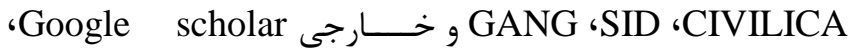
bread مورد جستجو قرار كرفتند. r- استفاده از وازههاى PubMed

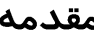

نان قوت غالب جمعيت بيشمارى در جهـان اسـت بطوريكـهـ ميـزان

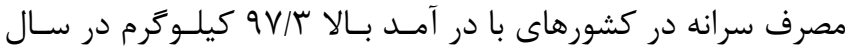

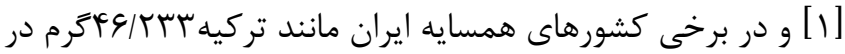

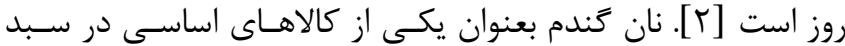

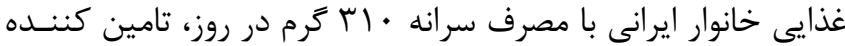

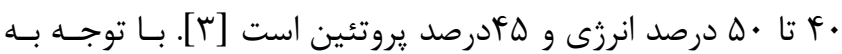
ميزان مصرف و ذائقه ايرانيان، نان داراى تنوع بسيارى است و همين مسئله از دير باز موجب شده است كه به انواع صنعتى و توليد بيشتر

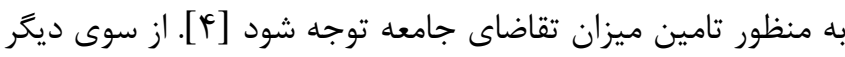
با توجه به اينكه عمده انرزى دريافتى اقشار آسيبيذير جامئ تامعه از نان

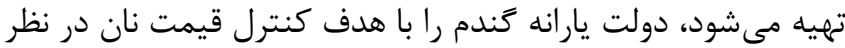

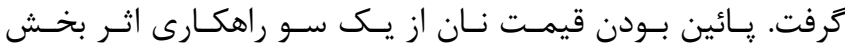

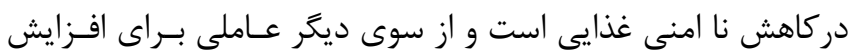

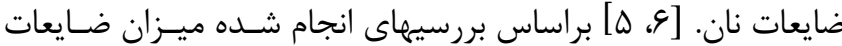

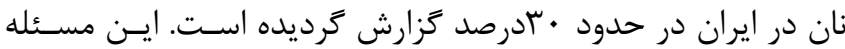

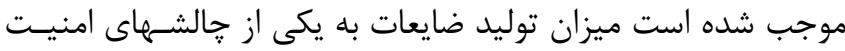

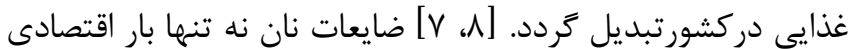

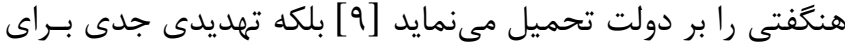
سلامت جامعه بشمارمى رود [• [1]. از جمله مـواردى كـهـ در ايجـاد روند نزولى در بياتى نان و كاهش ضايعات قابل ذكراست، بطور حتم

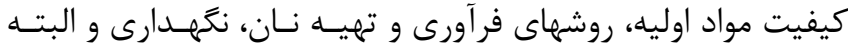

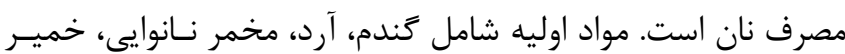

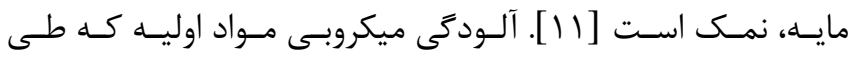

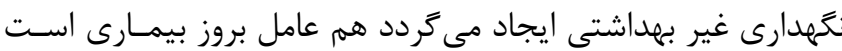

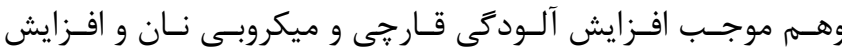
ضايعات مى كردد. مطالعات بسيارى به منظور بررسى عوامل مختلف

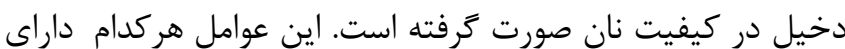

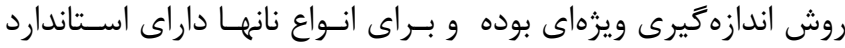

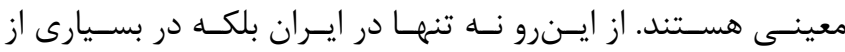

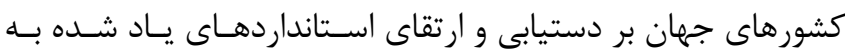
منظور بهبود كيفيت صنعت نان توجه ويـزّاى مسى كـردد. در ايـران

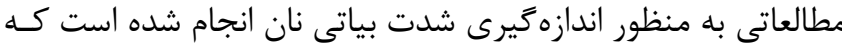

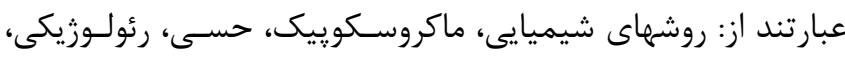

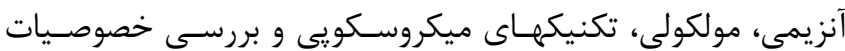

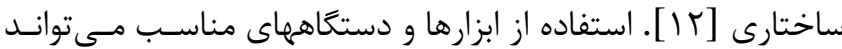


يرسشهاى مد نظر در تعيين كيفيت مقالات: ا - مقاله در كجا منتشر

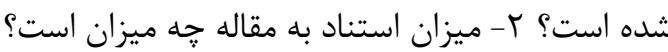

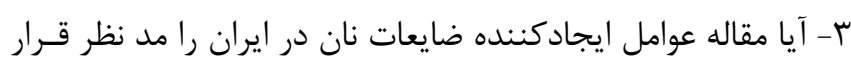

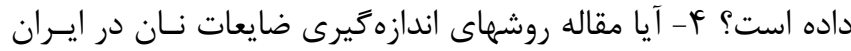

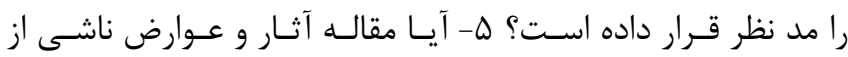
ضايعات نان در ايران را مد نظر قرار داده است؟ داده است

يافتهها

طى جستجوى ابتدايى تعـداد أFF مقالـه اسـتخراج شـد و مقـالات مربوط به جستحوى دستى از موتورهـاى جسـتجوى بـينالمللـى و

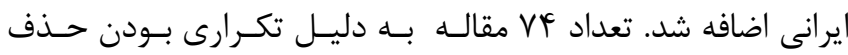

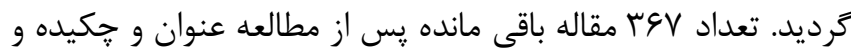

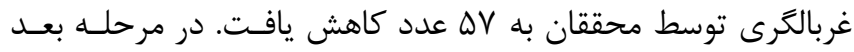

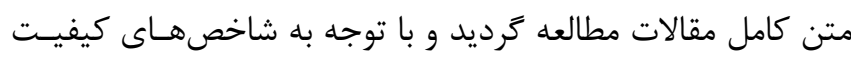

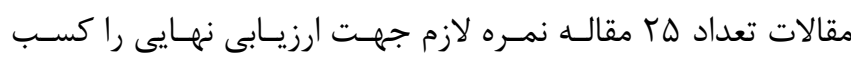

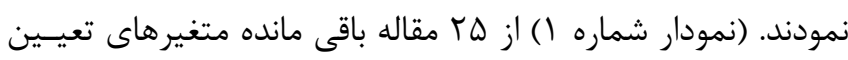
شده در خصوص ضايعات نان شامل عوامل ايجـاد كنــده، روشـهاى مهاى ارزيابى و نتايج و عوارض ايجـاد شـده، اسـتخراج گرديـد. اطلاعـات مربوط به يافته هاى حاصل از مقالات مشاهدهاى (تعداد ب امطالعـهـ) [IV-YG

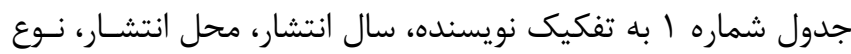

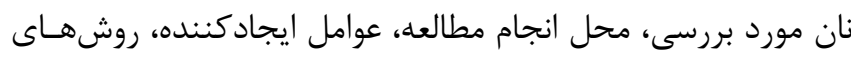

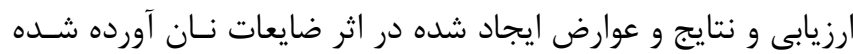

است.

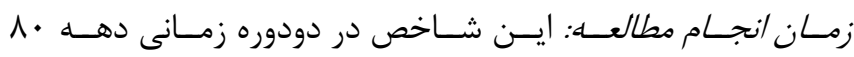

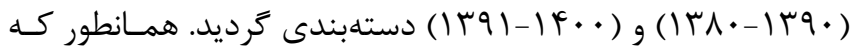

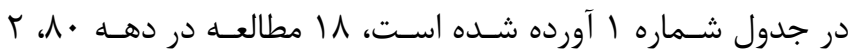
مطالعه در دهه • 9 ودر ه مقاله به زمان انجام مطالعه اشارهاى نشده

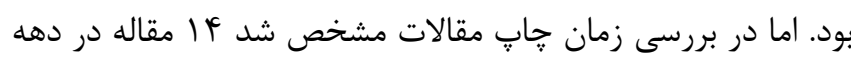

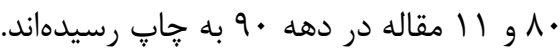
محققان: در بررسى محققين مجرى مطالعات، مشخص شد تعـدادى

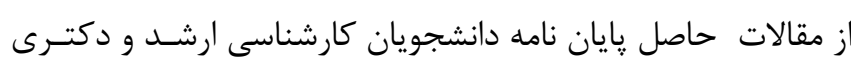
بود، و تعدادى بصورت طرح تحقيقاتى ارائه شـده بـوداين يزوهشـهـا اغلب توسط اساتيد دانشخاهها طراحى و اجرا شده است.

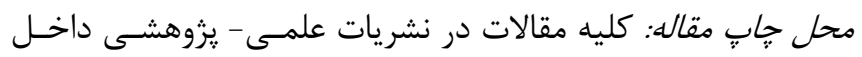

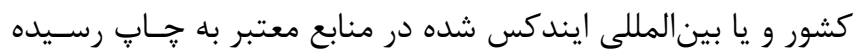
اندكه است كه در بخش موتورهاى جستجو شرح داده شده است. wastage, quality, type، traditional, industrial production, Iran

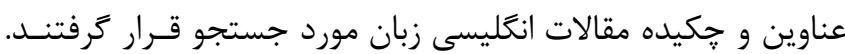

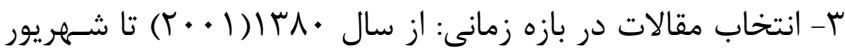

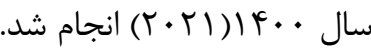

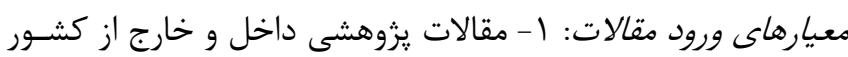

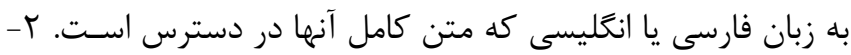
مقالاتى كه در آنها به روشهاى اندازهخيرى، ميزان ضايعات و عوامـل

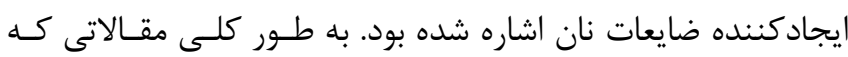

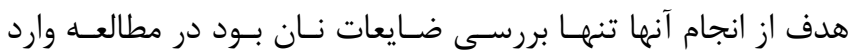

شدند.

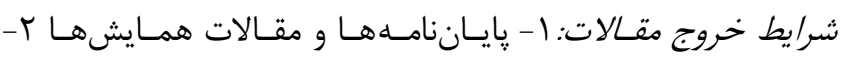

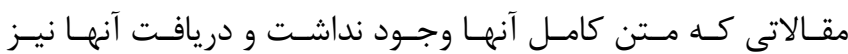
امكان يذير نشد. ب- مقالاتى كه به رغم بررسيهاى مختلف روى نه نـان به ضايعات اشارهاى نكرده بودند. موتورهـاى جسـتجو - موتورهـاى جسـتجو در ايسن مطالعـه شـامل (PubMed ،Google scholar ،GANG ،SID ،CIVILICA) يزوهشگاه علوم و فناورى اطلاعات ايران بود. روش جستجو: به منظور دسترسى به مقالات ابتدا با توجه به وجـود بـون

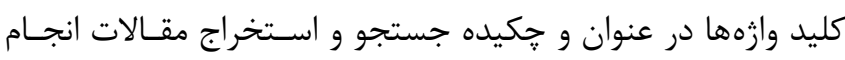
شده وسيس موارد تكرارى شناسايى و حذف گرديد. در مرحلـه بعـد متن كامل مقالات باقى مانده مطالعه و موارد غير مرتبط حذف شـد.

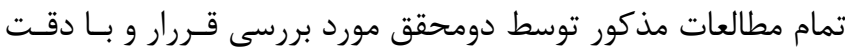
تعدادى از مقالات در نهايت انتخاب شدند.. در ميان مقالات باقى مانده نتـايج متغيـرهـاى مـورد نظــر در گــروه

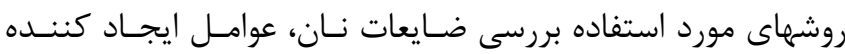

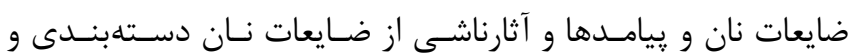

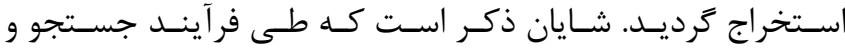
غربالكرى، تنها مقالاتى بررسى وبه مطالعه وارد شدند كه بـه عوامـل

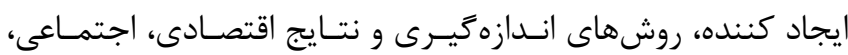

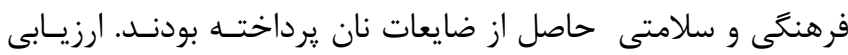
كيفيت مقالات: به منظـور ارزيـابى كيفيـت مقـالات انتخــاب شـده خصوصياتى توسط نويسند

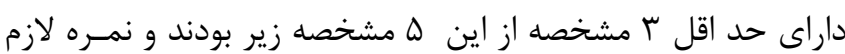
را كسب كردند با كيفيت قلمـداد شـده و دادههـاى آنهـا اسـتخراج گرديد. مقالات با نمره كمتر از ب حذف گَرديد. 
مرتبط با مواد اوليه r- عوامل مربوط به عرضه كنندكان نان (نانوايى)

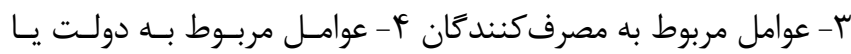

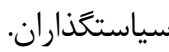

1- عوامل مرتبط با مواد اوليه: استفاده از خمير ترش با تـاثير مثبــت

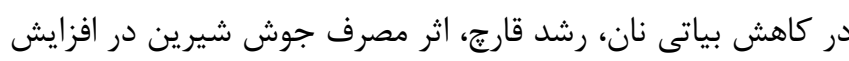

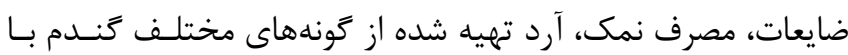
درصد متفاوت كلوتن، فيبر، استحصال

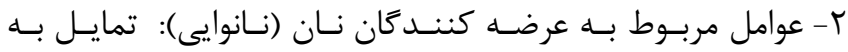

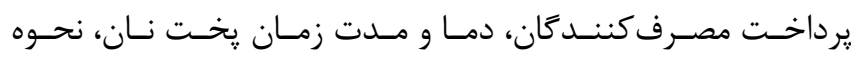

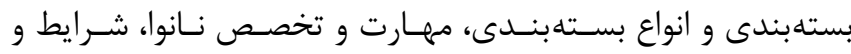

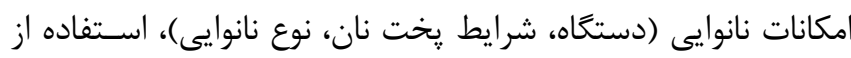
سهميه آرد دولتى نسبت به آرد آزاد.

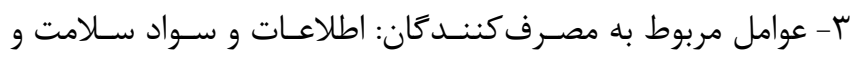
آموزش مصرف كنندكان، رفتار مصرفكنيدكان، شرايط نتحهدارى نان توسط مصرفكنندًان، دفعات مراجعه به نانوايى در هفته، تعداد نان

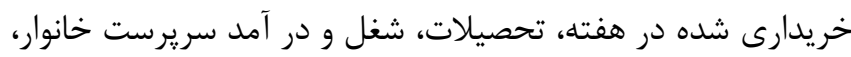

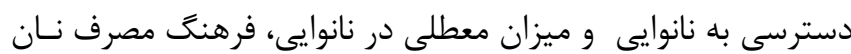

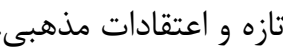

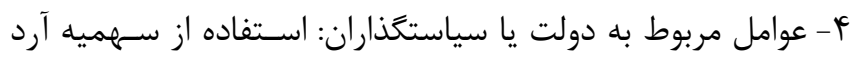

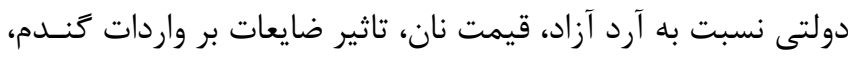
كاهش فقر، امنيت غذايى، تعداد نانوايى در منطقه.

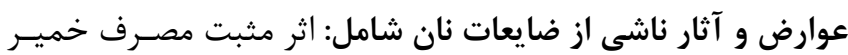

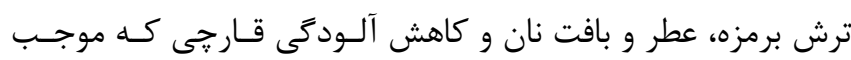

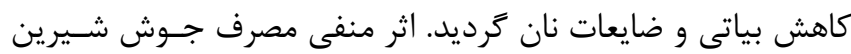
(بى كربنات سديم) بر افزايش خاصيت قليايى و PH نـان و افزرايش

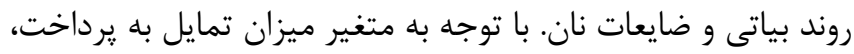

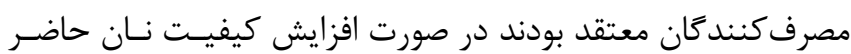

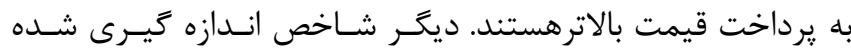

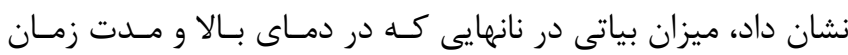
كمتر קخت شدند كمتر است.در بررسى اثر انواع بسته بنديى نان در دران

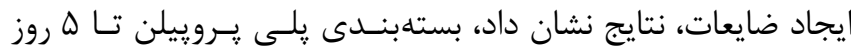
خصوصيات كيفى نان بخصوص نوع تافتون را حفظ نموده است. امـا

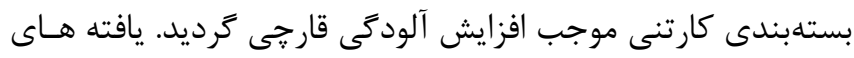

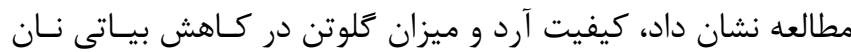

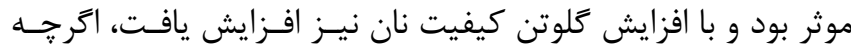

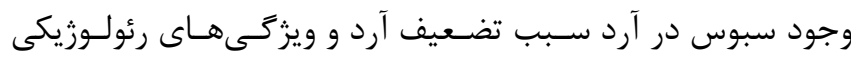

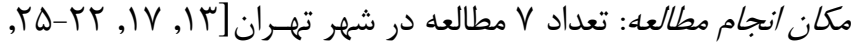

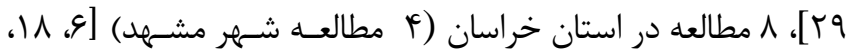

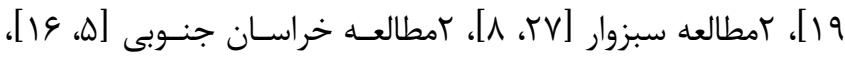

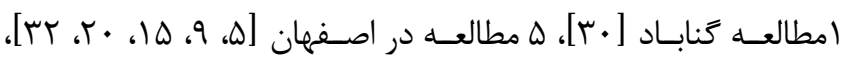

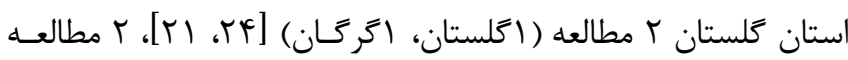

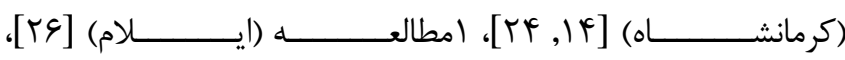

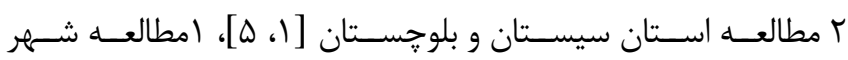

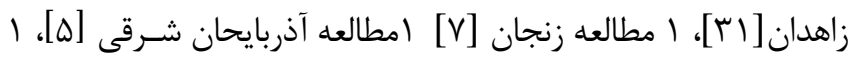

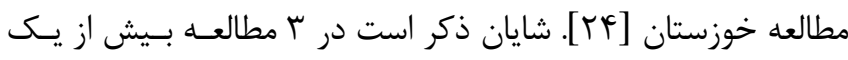

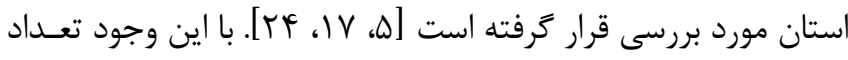

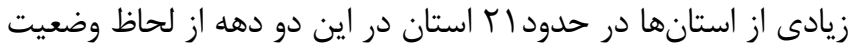
ضايعات نان مورد مطالعه قرار نكرفتنه اند.

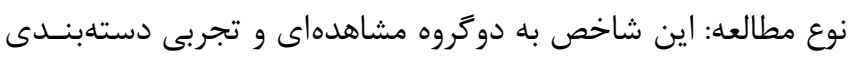

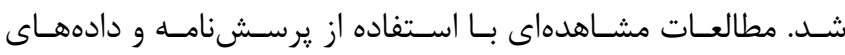

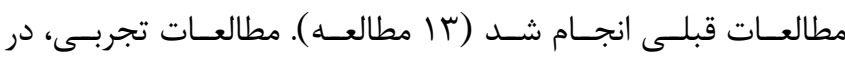

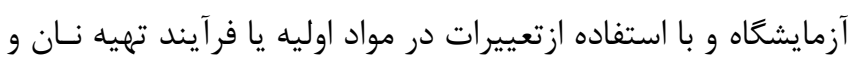
بررسى توليـد ضـايعات صـورت كرفـت (r ا مطالعـه) .اطلاعـات در جدول ا كزارش شده است.(جدول ().

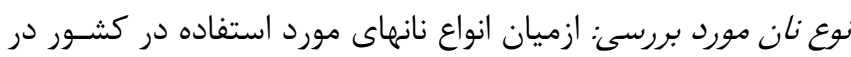

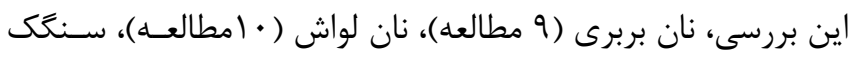

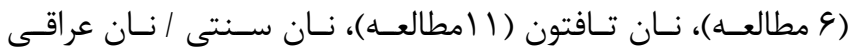

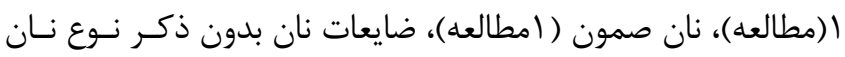

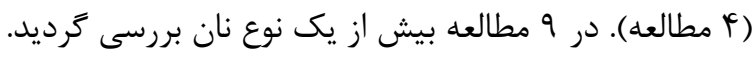

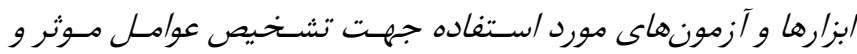
ميزان ضايعات نان: مطالعات در سه دسته تقسيمبندى شد و شامل:

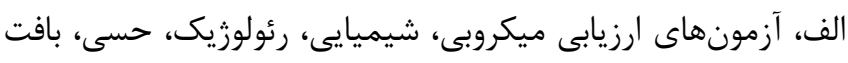

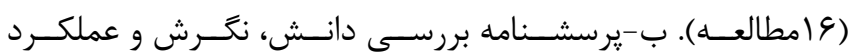
مصرفكنندكان و نانوايان و קكى ليست ارزيسابى نـانوايى و عملكـرد

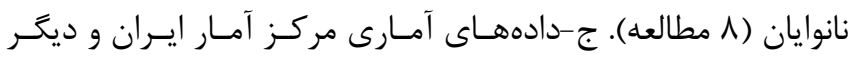

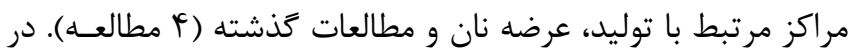

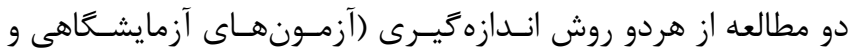
برسشنامه) استفاده كرديد.

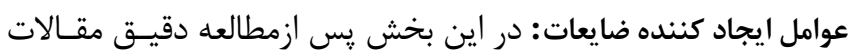

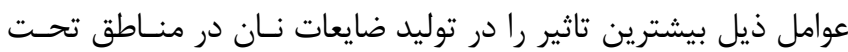

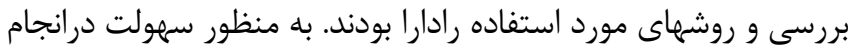

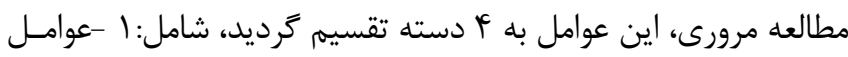


نشريه يروهشكده علوم بهداشتى جهاددانشكاهى

مصرفكنندگان نان يارانهاى دسترسى آسان بيان شد. در حاليكه در

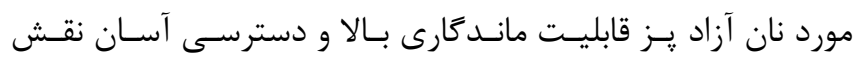
داشت. مصرف كنندگان معتقد بودند نانوايىهاى فروش نان آنان آزاد، نان

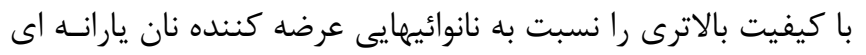
عرضه مىنمايند. در بعد عوامل اقتصادى و اجتماعى، ارتباط مثبت بين افزايش توليد

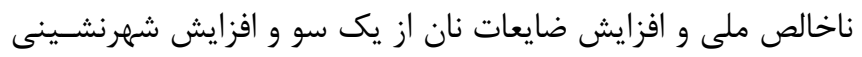
با افزايش ضايعات نان از سوى ديكر قابل ملاحظـهـه بـود. نكتـه قابـل تامل ديخر،ارتباط كاهش ضايعات نان با كاهش فقر و افزايش امنيت غذايى بود. همجنين به ارتباط منفى ضريب جينى و ضـايعات نـان

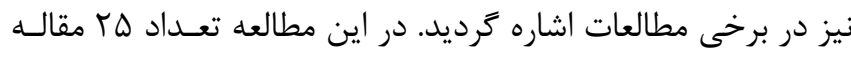

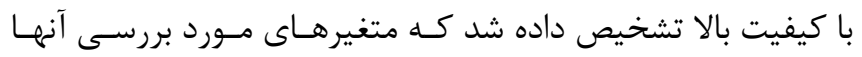

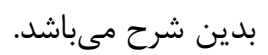

مىشود. اما از سوى ديگر، آرد با درجـهـ اسـتخراج بـالاتر و سـبوس بيشتر داراى رتروگرادسيون و زلاتينه شـدن كمتراسـت، در نتيجـهـ

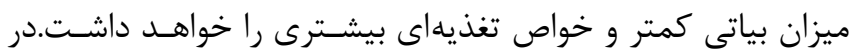
بخش توليد و عرضه نان، متغير سطح آكاهى نانواها در مورد فرآينـد

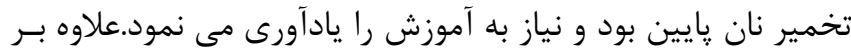

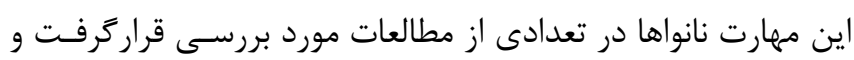
مشخص شد در استفاده از خمير ترش، عدم مصرف جوش شـيرين، نكمهدارى مناسب آرد و اهميت تنظيم حرارت و دماى مناسب بـراى

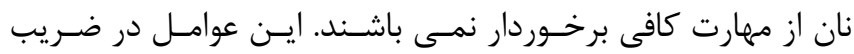

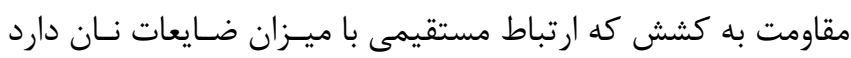
تاثير گذار است. در تمامى استانهاى مورد بررسى ضـايعات نـانهـا

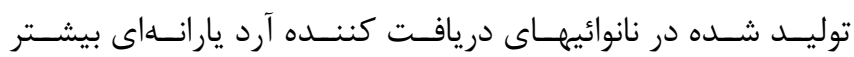

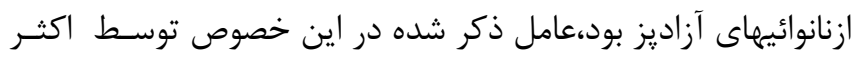

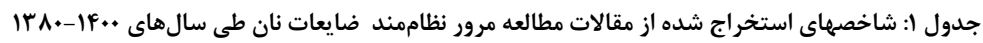

\begin{tabular}{|c|c|c|c|c|c|c|}
\hline نتايج حاصل از يزوهش & نوع آزمون، ابزار سنجش & مداخله، ارزيابى، متغير & مكان & 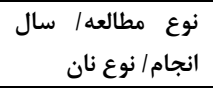 & 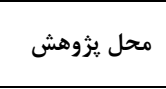 & سال انتشار \\
\hline 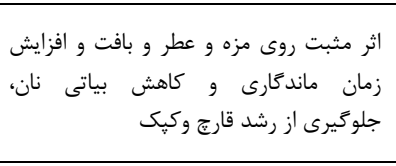 & 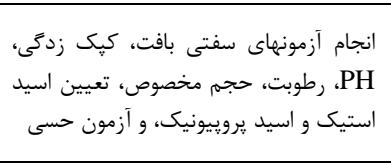 & 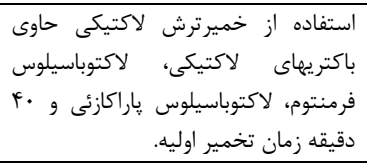 & آزمايشَاه & تجربى/هף ||، بربرى & سبزوار & رسبوبه سادات سيده \\
\hline 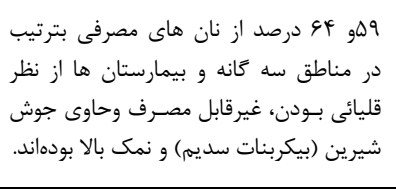 & آزمون نمك، PH، رنك سنجى & 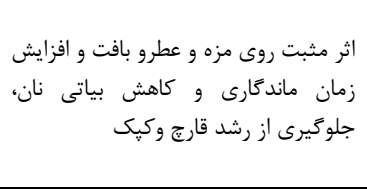 & بيمارستان & 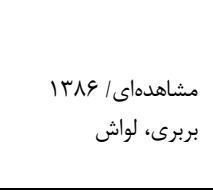 & شهر شتان & 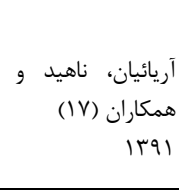 \\
\hline غنان & 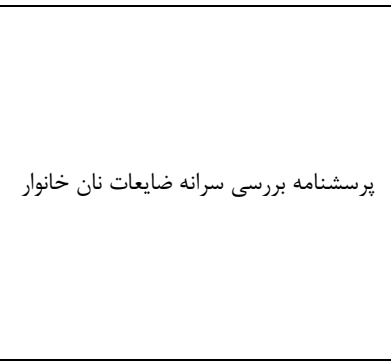 & 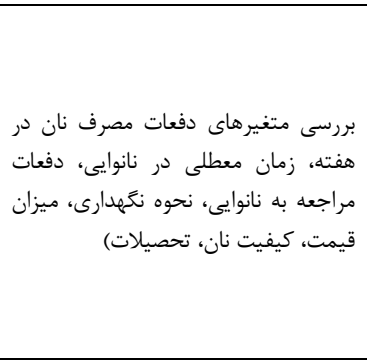 & خانوار & 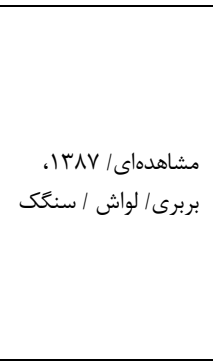 & مشهد & 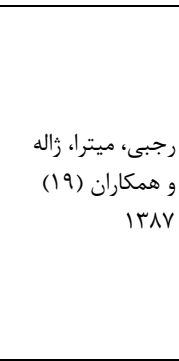 \\
\hline 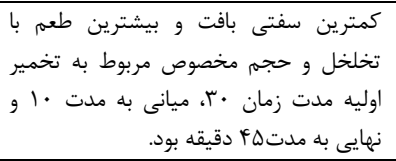 & مخصوص، خصوصيات حسى نان مغز نان، حجم & 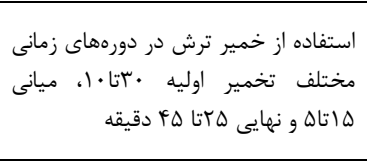 & آزمايشكاه & 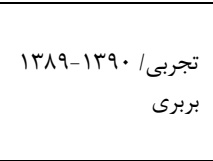 & مشهد & 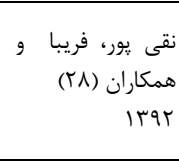 \\
\hline 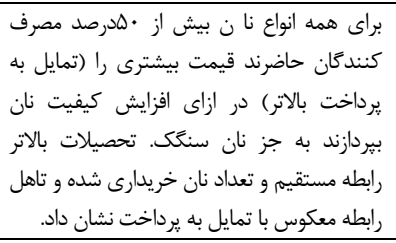 & استفاده از يرسشنامه تمايل به برداخت & مقابل افزايش كميفيت نان مصرفنده به يرداخت در & مسير نانوايى & 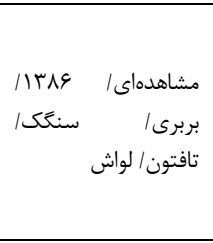 & اصفهان & 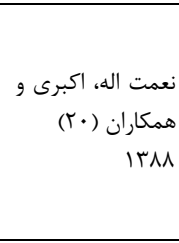 \\
\hline 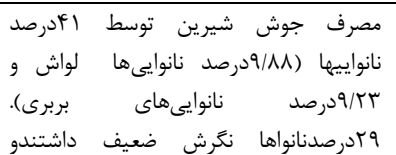 & رآزمايش نانه آكاهى، نكرش و عملكرد و انجام & آزمايش شيمياييى و و الكتروشيميايى & آن & 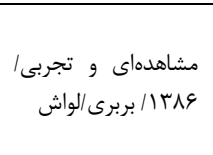 & كركان & 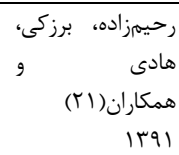 \\
\hline
\end{tabular}


سال بيستم، شماره ششم، آذر ـدى ..

كودرصد آكاهى متوسط و • ا در صد آكاهى

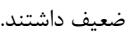

نانهايى كه در زمان طولانى و دمانى كمتر

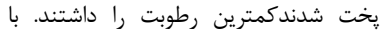

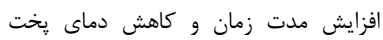
ميزان نشاسته محلول در نان افزايش مي ميابد.

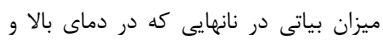
مدت زمان كمتر يخت شدندكمتر است.

بررسى دماوزمان پِخت بر كيفيت و آزمون تعيين رطوبت، بياتى و ميزان نشاسته محلول نكمدارى نان

زآمايشگاه

تجربى/

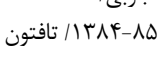
|صفهان قنبرى، مسعود همكاران (1) (1) IrNV

بستهبندى كارتنى تفاوت معنى دارى را در

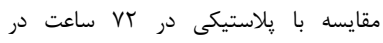

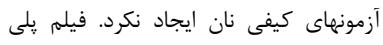

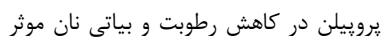

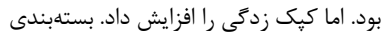

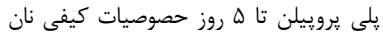
بخصوص تافتون حفظ مىشود

در حدود 1זدرصد نانهاى تافتون كيفيت لازم را براى مصرف نداشتند. آموزش نانواهونا نافيا

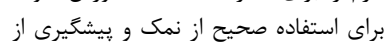

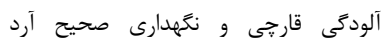

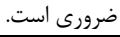

سه روش بستهبندى ا-يلى اتيلن دولايه،

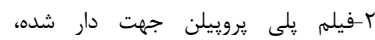

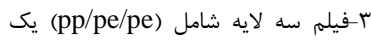

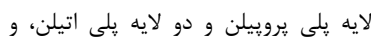

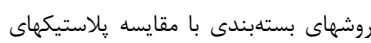
ذكر شده و كارتن انجام شد. و مقايسه بسته بندي

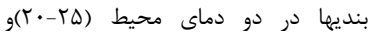
(F)

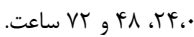

سه روش بستهبندى ا-يلى اتيلن دولايه،

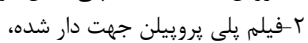

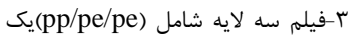

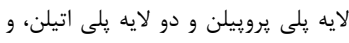

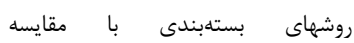
يلاستيكهاى ذكر شده و كارتن انجام شد.

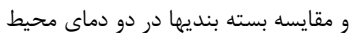
د زمان

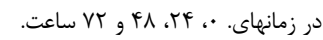

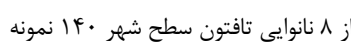

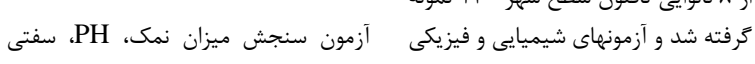

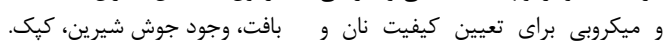
ضايعات انجام شد.

همكاران (9)

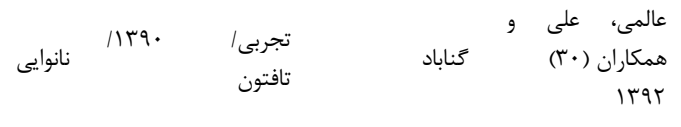

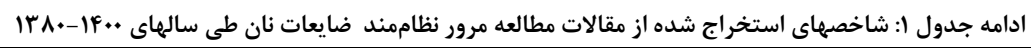

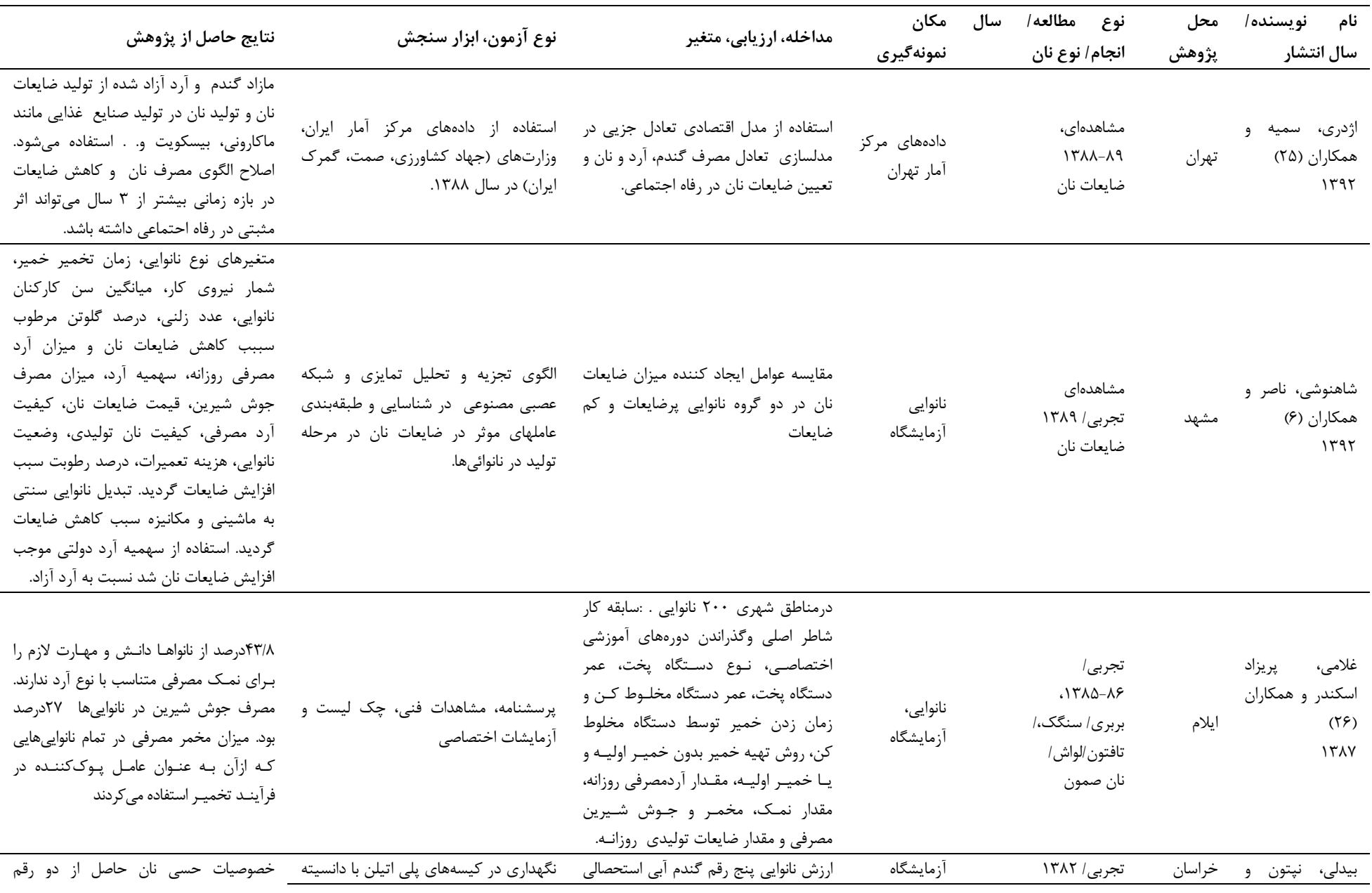


سال بيستم، شماره ششم، آذر - دى ..

نشريه يزوهشكده علوم بهداشتى جهاددانشاهى

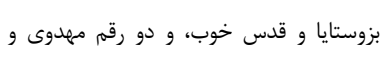

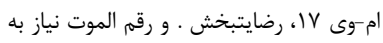

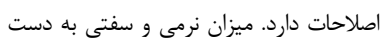

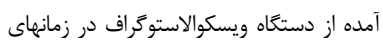

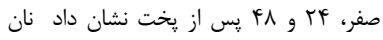

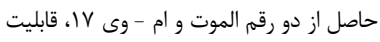

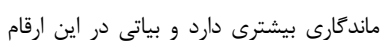

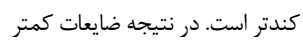

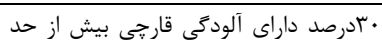

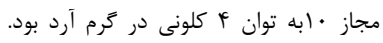

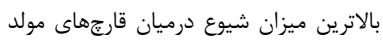

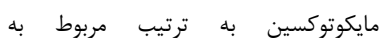
آكرومونيوم و در آسيرزيلوس فوميكاتوس برسي

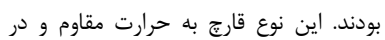

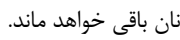

خمير بدست آمده از آرد كندم مهدوى ضريب

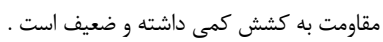

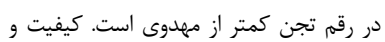

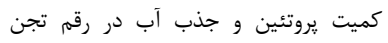

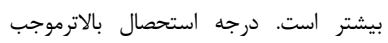

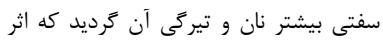

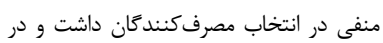

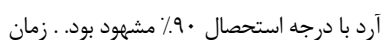

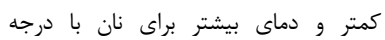
استحصال بالاتر مناسبتر است.

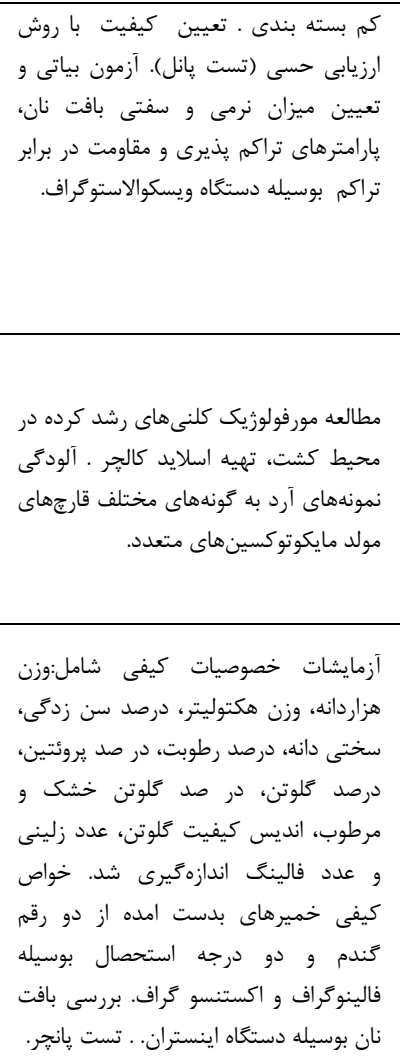

مطالعه مورفولوزيك كلنىهاى رشد كرده در محيط كشت، تهيه اسلايد كالجر ـ آلودئى

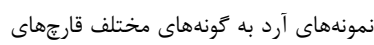
مولد مايكوتوكسينهاى متعدد.

آزمايشات خصوصيات كيفى شامل:وزن

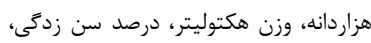

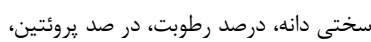

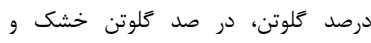
مرطوب، انديس كيفيت تملوتن، عدد زلينى دراني

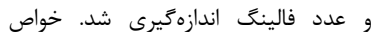
كيفى خميرهاى بدست امده از دو دو رقم كندم و دو دو درجه استحصال بوسيله فالينوكراف و اكستنسو كراف. بررسى بافت

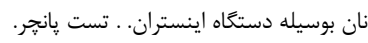

بررسى سا 11 نمونه آرد از نانوائىهاى سطح

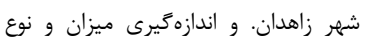

قارج در آردهاى موجود در انبار نانوائيها.

نانوايى

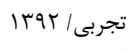
آرد ابراهيم زاده، عادل
دو رقم كندم مهدوى و تجن و با دو درجه

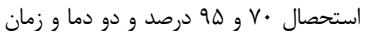

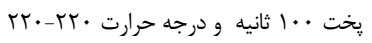

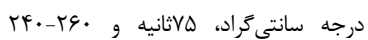

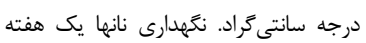

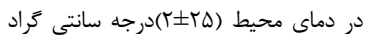

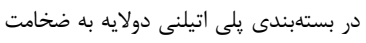

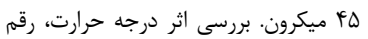

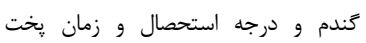
برميزان بياتى نان و خواص حست حسى، نمونهال

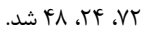

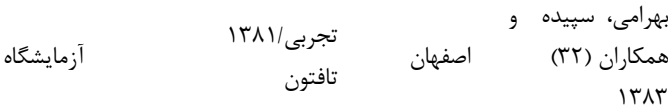

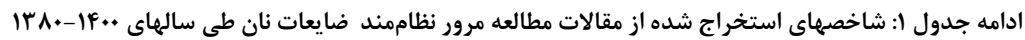

\begin{tabular}{|c|c|c|c|c|c|c|}
\hline نتايج حاصل از يزوهش & نوع آزمون، ابزار سنجش & مداخله، ارزيابى، متغير & مكان نمونهكيرى & انجام/ مطالعه/ مال مال & محل يزوهش & سال انتشار \\
\hline 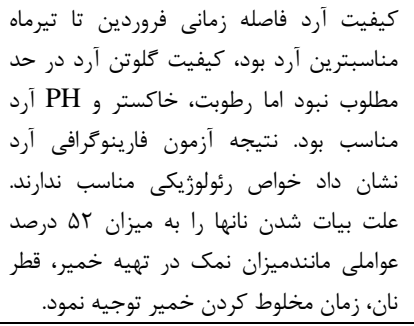 & 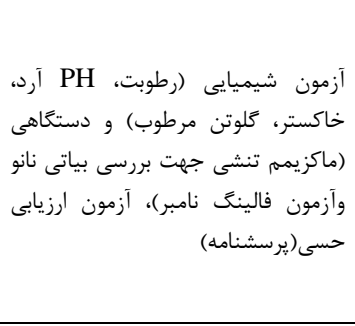 & 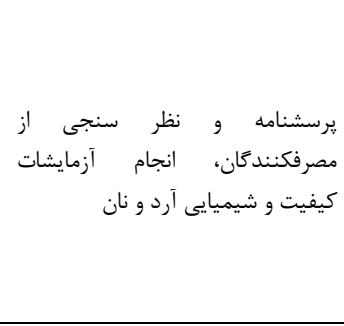 & نانوايى، آزمايشكاه & تجربى/سوساى|| & سبزوار & 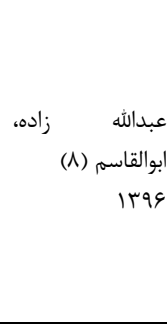 \\
\hline 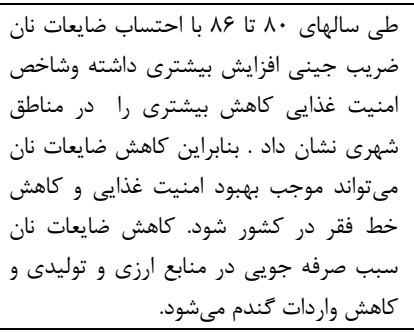 & 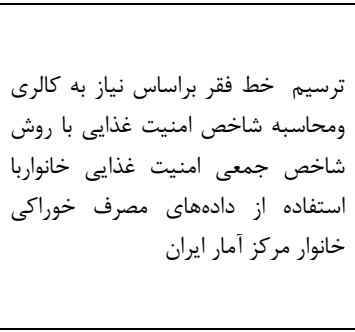 & 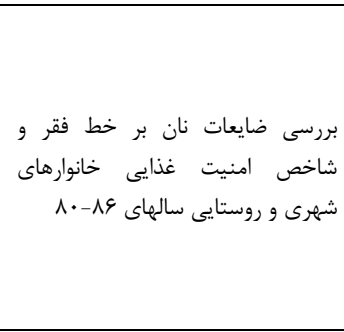 & تهرانهاى مركز آمار & 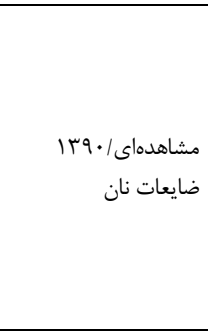 & تمهران & 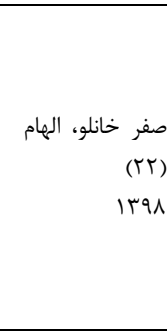 \\
\hline 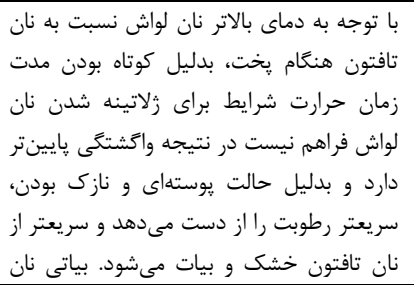 & 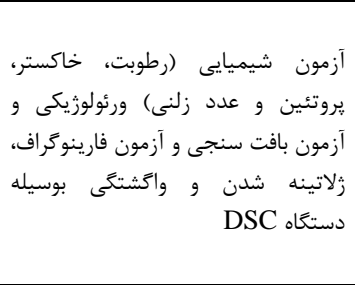 & 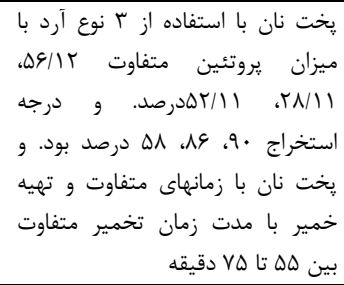 & آزمايشكاه & 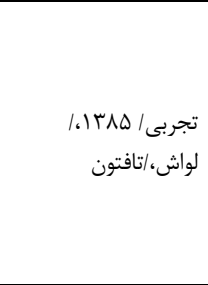 & تمهران & 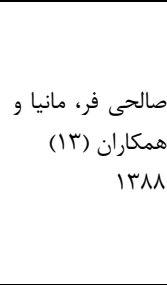 \\
\hline
\end{tabular}


سال بيستم، شماره ششم، آذر -دى .. If

لواش از نان تافتون بيشتر است.

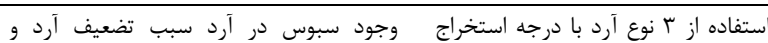

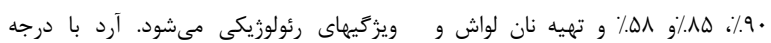

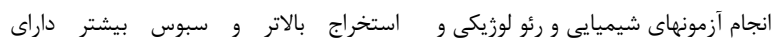

رتروكرادسيون و زلاتينه شدن كمتراست، بياتي

كمتر و خواص تغذيهاى بيشتر دارد. امادر نان

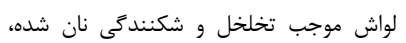
كيفيت آن را كاهش ميى دهد،

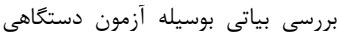

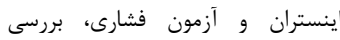

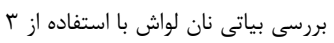

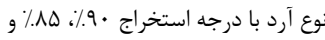

زلاتينه شدن و رتروخرداسيون بوسيله

$\therefore$ : $\%$

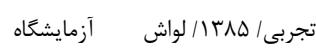

صالحى فر، مانيا و

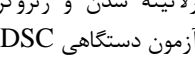

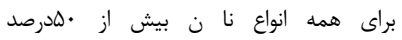

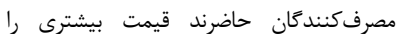

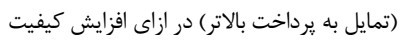

نان بيردازند به جز نان سنحكى. تحصيلات بالاتر

رابطه مستقيم و تعداد نان خريدارى شده و تاهل

ستفاده از يرسشنامه تمايل به يرداخت

بررسى تمايل مصرفكننده به يرداخت

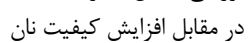

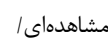

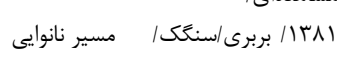

تافتون/ لواش بري

اميدوار، نسرين و و (بمار)

همكاران (Tr)

IrNG

رابطه معكوس با تمايل به يرداخت نشان داد.

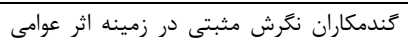

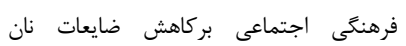

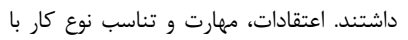

تخصص نانواها در كاهش ضايعات نان موثر بود.

بالابودن سطح تحصيلات مردم اثر مثبتى در نابر

افزايش ضايعات نان داشت. رابطه منفى بين بين مردين

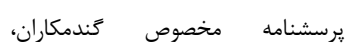

نانوايان، مصرف كنندكان
بررسى نَرش گَندمكاران؛ نانوايان، و

مصرفكنندًان در زمينه عوامل موثر بر كاهش ضايعات نان
مزرعه، انوايى،

خانوار
مشاهدهاى| (مإن

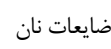

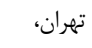

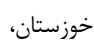

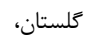

كرمانشاه

بيخى، ، على

همكاران (TF) بئى

IrNV

ارتباط مثبت بين تعداد نان خخته شده و ميزان

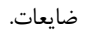

زنان خانوادههاى ير درآمد كمترين توجه را به

مصرف صحيح نان داشتند. نان لواش سنتى دارئ داري

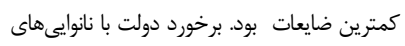

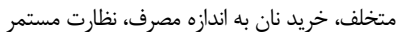

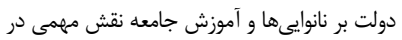

يرسشنامه بررسى آكَاهى و عملكرد زنان

خانه دار در مورد وضعيت مصرف نان و ورنان

بررسى ديدكاههاى زنان خانهدار در

مورد وضعيت مصرف نان و راهكارهاى زنان

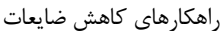

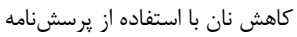

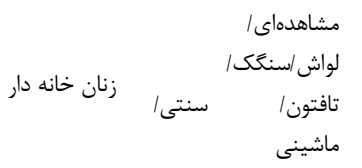

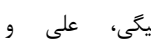

كرمانشاه همكاران (If)

1 1 كاهش ضايعات داشت

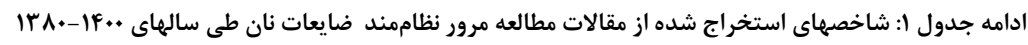

\begin{tabular}{|c|c|c|c|c|c|c|}
\hline نتايج حاصل از يُوهش & نوع آزمون، ابزار سنجش & مداخله، ارزيابى، متغير & مكان نمونه گَيرى & انجام/ نوع نان مطالعه/ سال & محل يزوهش & نام نويسنده/ سال \\
\hline 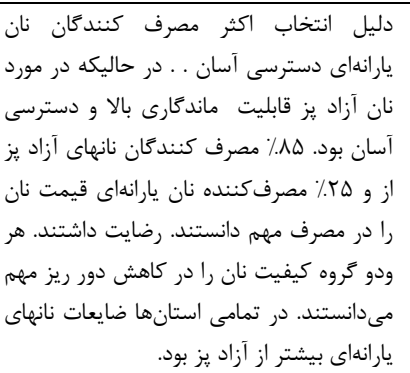 & 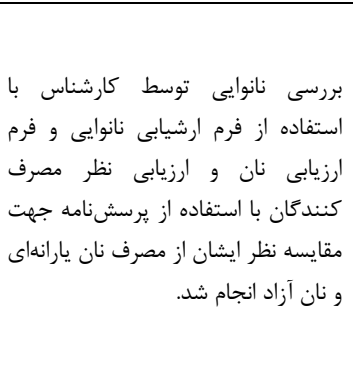 & 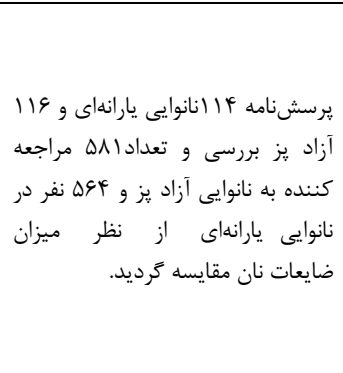 & 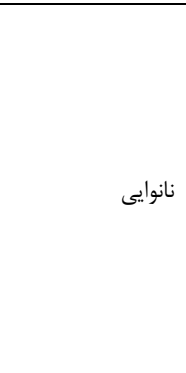 & 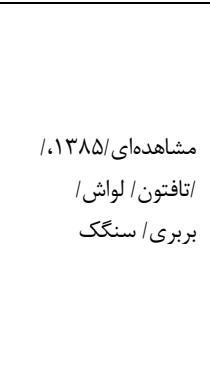 & 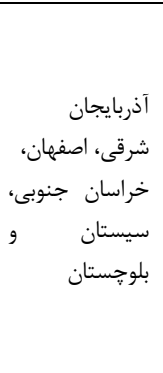 & 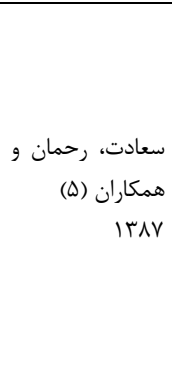 \\
\hline 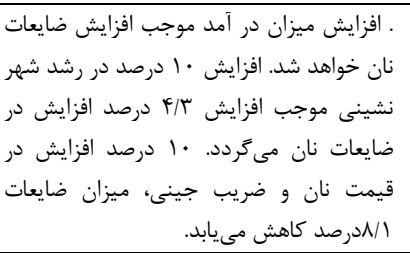 & 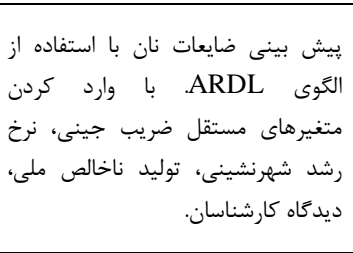 & 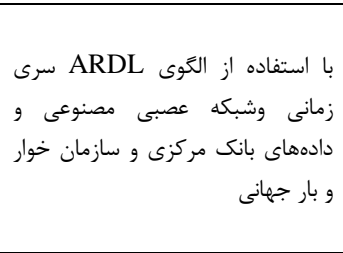 & 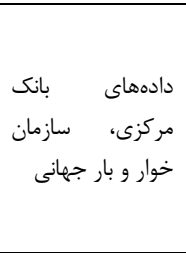 & مشاهدهاى/ مشات نان & مشهد & 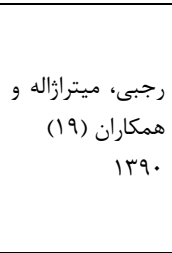 \\
\hline 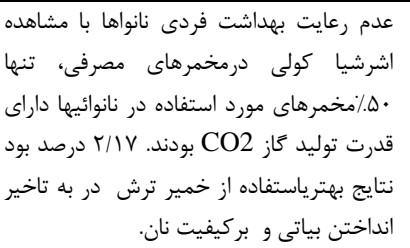 & 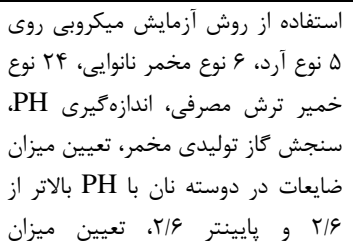 & 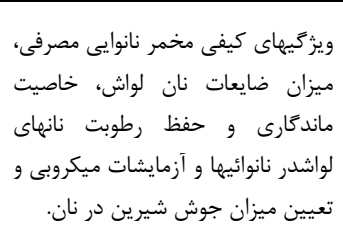 & نانوايى، & تجربى نان لواش & 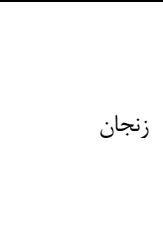 & 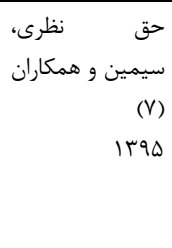 \\
\hline
\end{tabular}


سال بيستم، شماره ششم، آذر -دى .. If

نشريه يزووهكده علوم بهداشتى جهاددانشخاهى

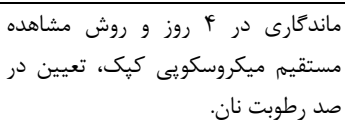

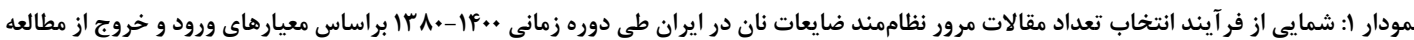

نتايج جستجوى اوليه مقالات فارسى و انخليسى

( $\mathrm{SID}=83$, civilica=76, Google scholar=150, PubMed =1)
تعداد مقالات حاصل از جستجو در منابع ديخر

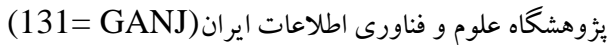

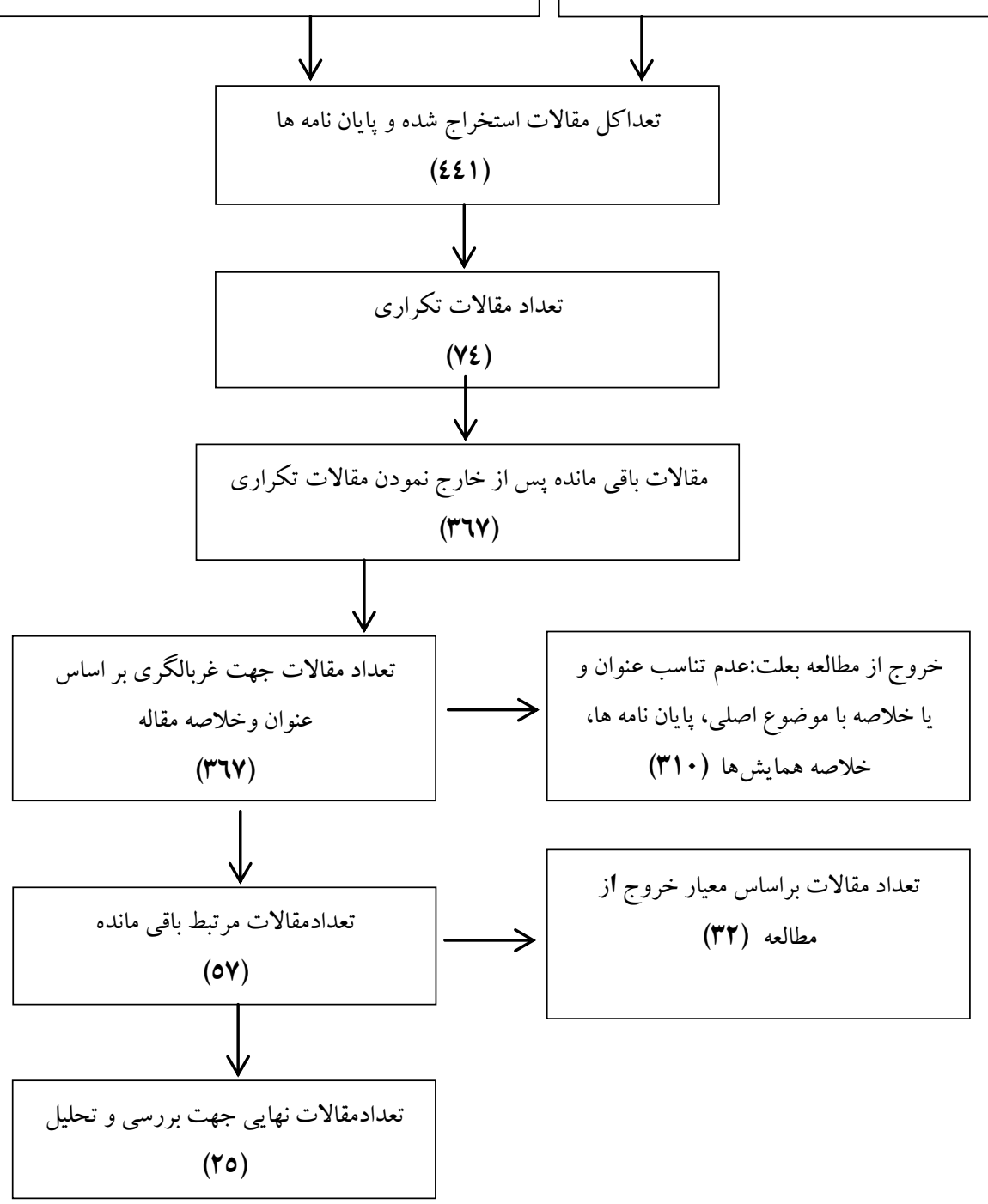




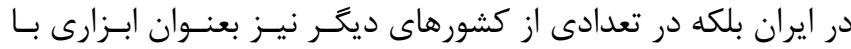

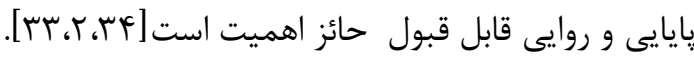

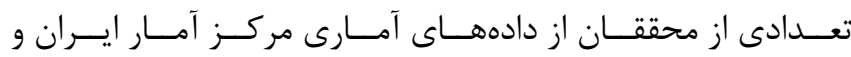

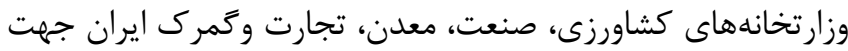

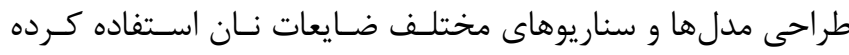

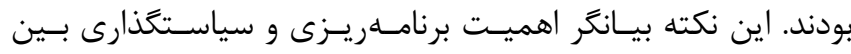

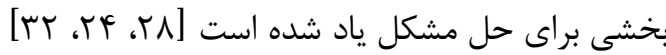
بررسى عوامل مختلف در ايجاد ضـايعات نـان نشـان داد اسـتفاده از خمير ترش و مخمر نانوايى اثر مثبت روى مزه، عطر، بافت، افزايش

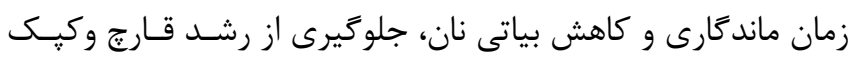
دارد [ V V] مطالعه انجام شده در استان ايلام نشان دادميزان مخمـر

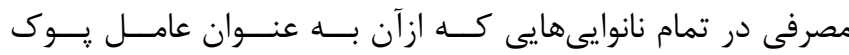

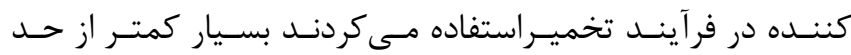

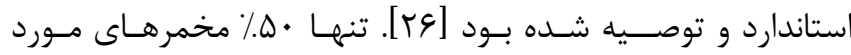

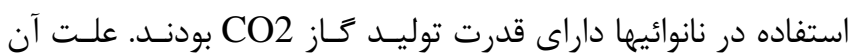

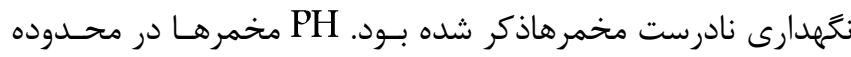

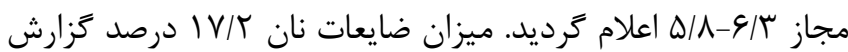
شد. استفاده از خمير ترش نتايج بهترى نسبت به استفاده از مخمـر

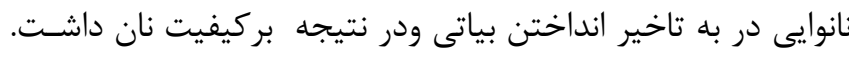

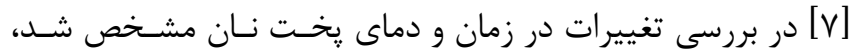

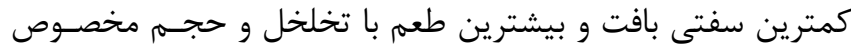

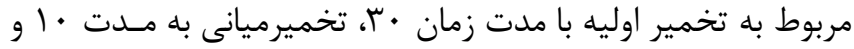

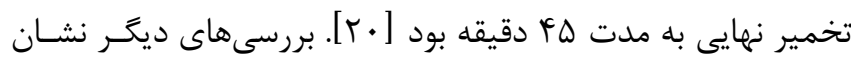

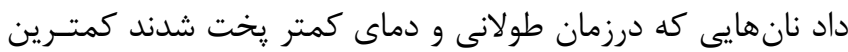

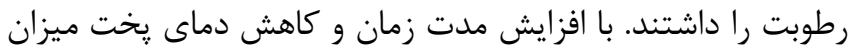

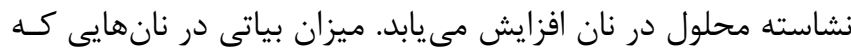

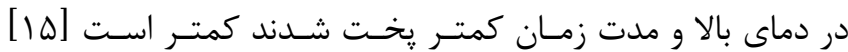

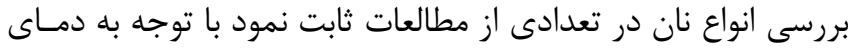

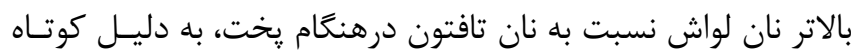

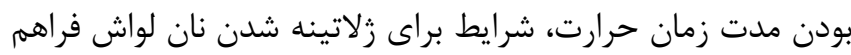

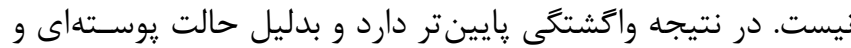
نازك بودن، سريعتر رطوبت را از دست مي دهد ودر نهايست سـريعتر

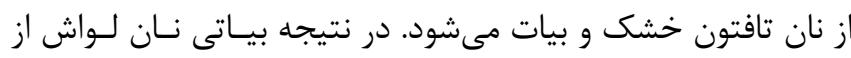

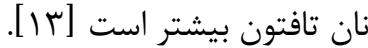
افرايش PH خمير مورد استفاده در تهيه نان در تعدادى از مطالعات بررسى گرديد. علت آن استفاده از جوش شيرين (بيكربنات سديم )

\section{بحث و نتيجه گيرى}

مرور نظاممند حاضر به بررسى اثر عوامل مختلف در توليـــ ضـايعات

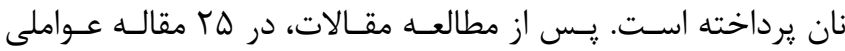

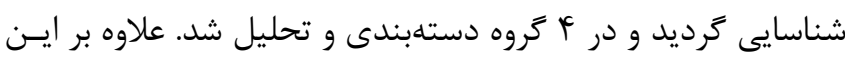

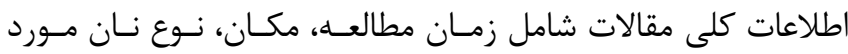

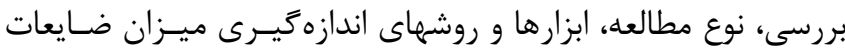

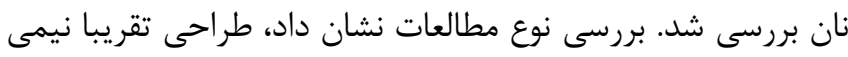

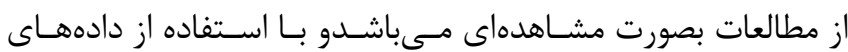

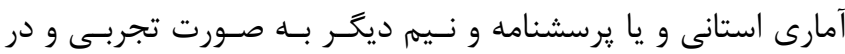

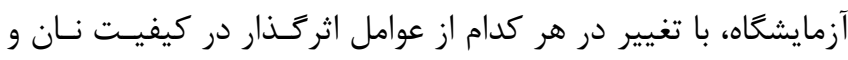

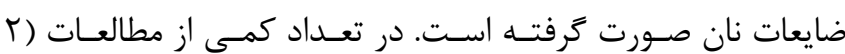

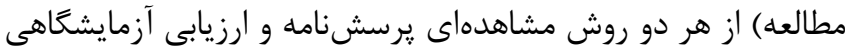

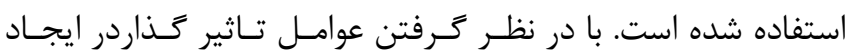

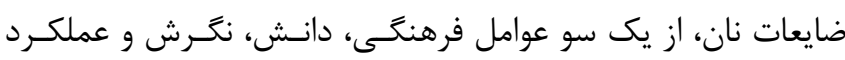

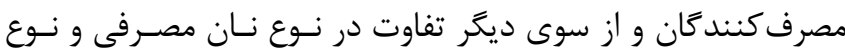

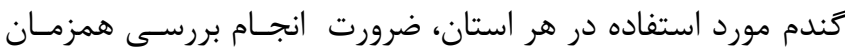

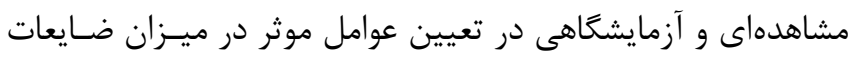

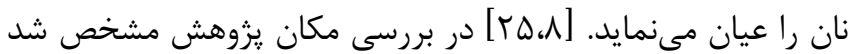

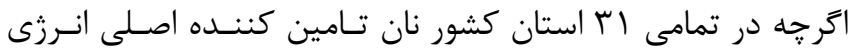

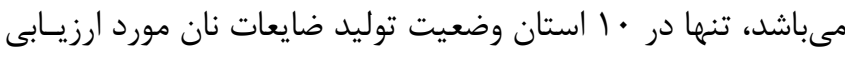

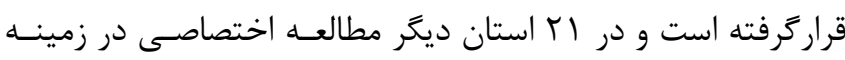

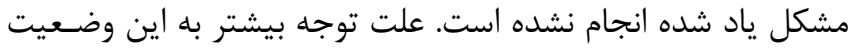
در استانهاى مورد بررسى، شايد وجـود دانشـكده تغذيـهـ و صــايع

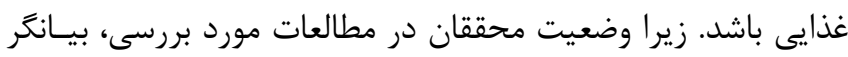

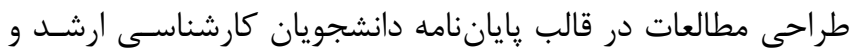

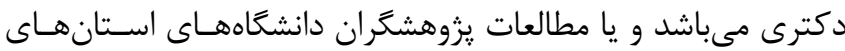

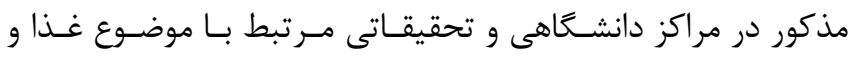
تغذيه است. مطالعه روشهاى مورد استفاده در ارزيابى عوامل مـوثر دئر در توليد ضايعات نان نشان داد آزمونهاى تعيين ميزان سفتى بافت

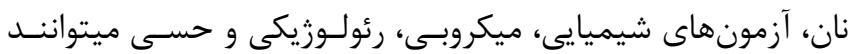

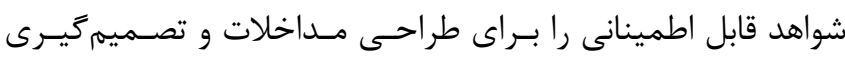

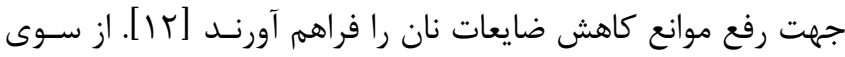

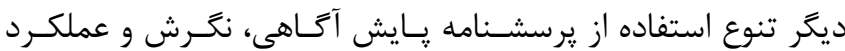

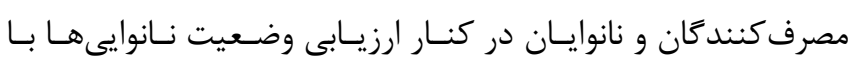

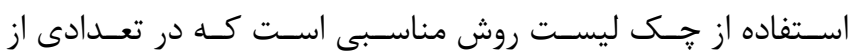

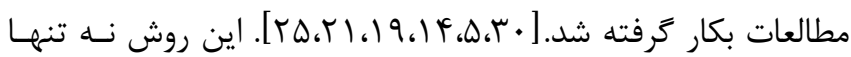


استخر اج بالاتر و سبوس بيشتر داراى رتروكرادسيون و زلاتينه شدن

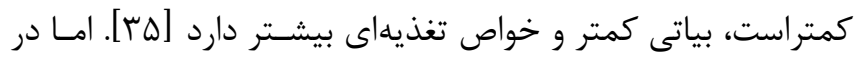

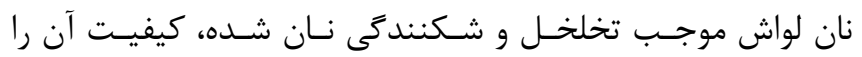
كاهش ميدهد، به دليل يوستهاى بودن نان لواش در نتيجه ضان إنايعات

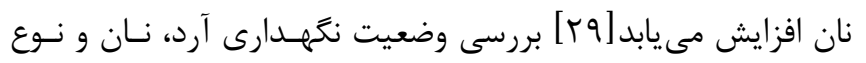

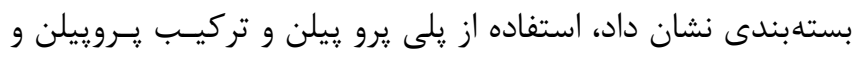

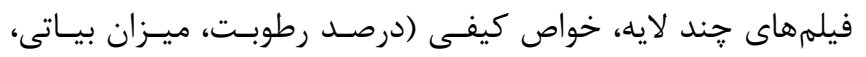

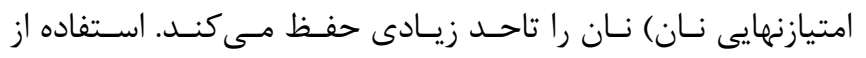

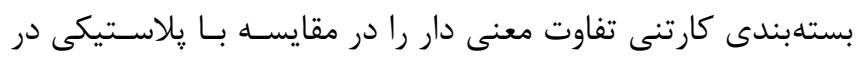

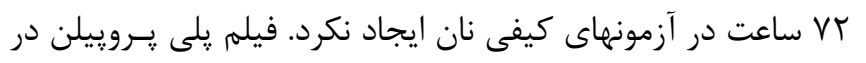

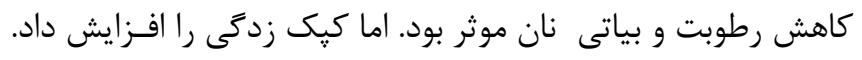

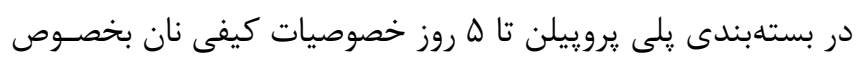

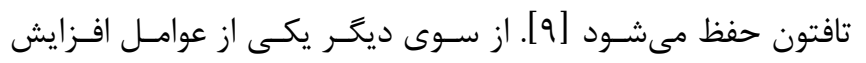

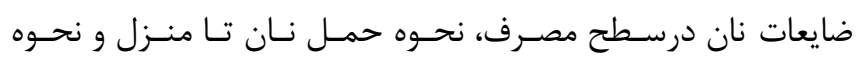

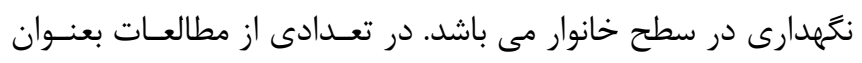

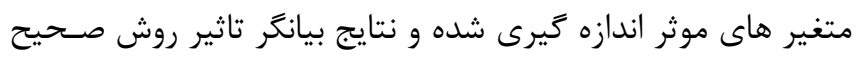

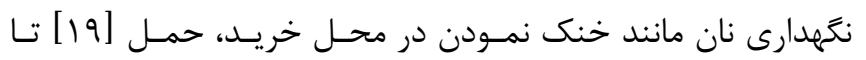

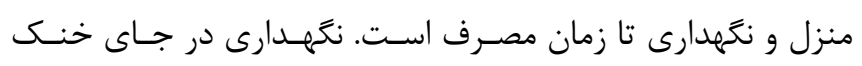

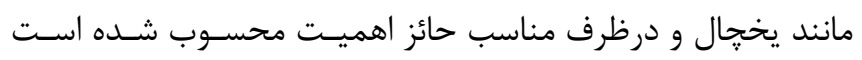

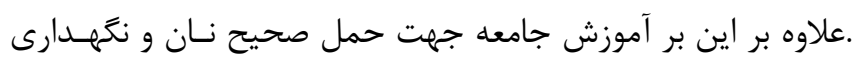

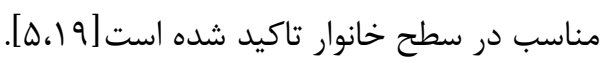

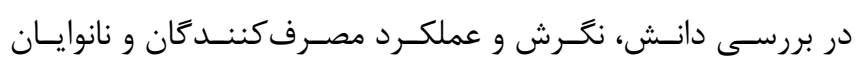

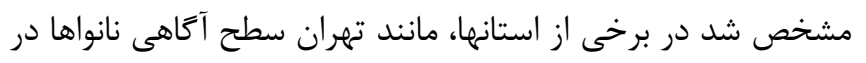

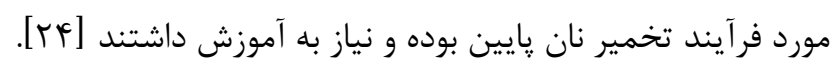

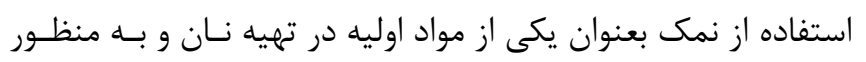

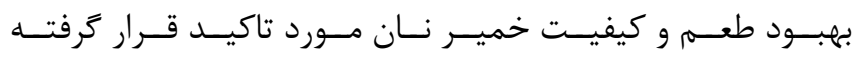

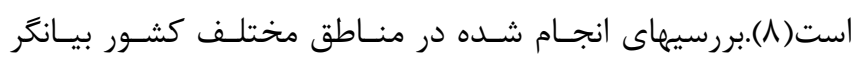

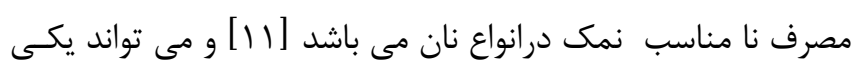

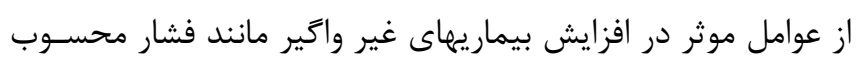

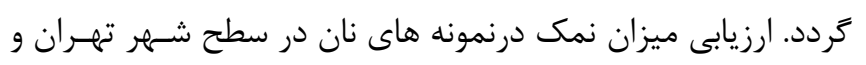

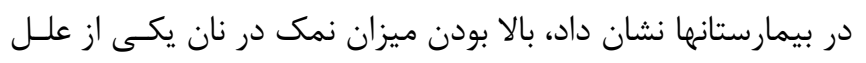

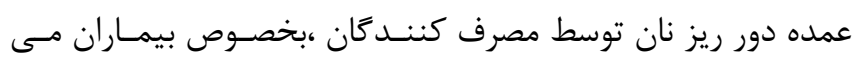

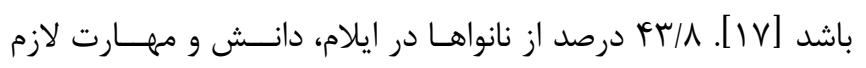

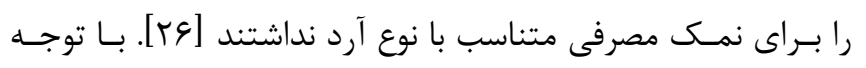

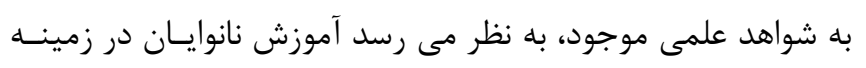

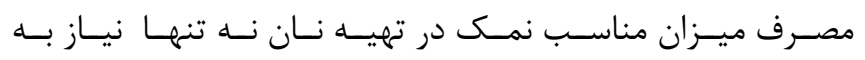

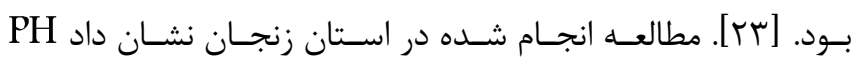

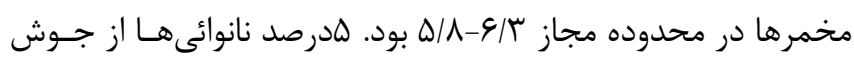

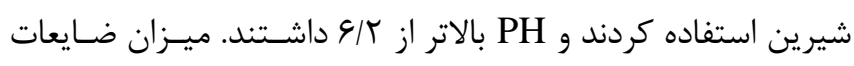

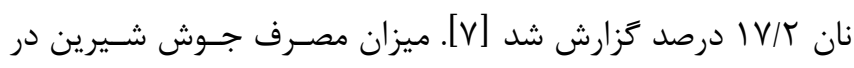

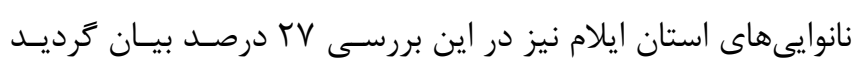

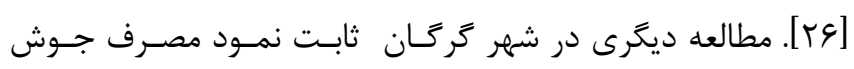

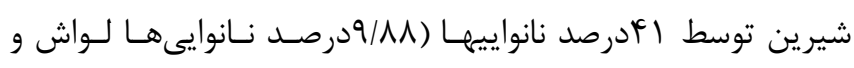

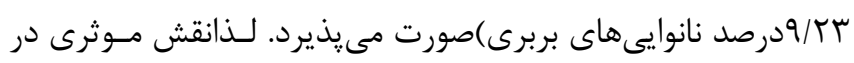

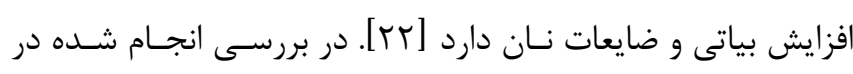

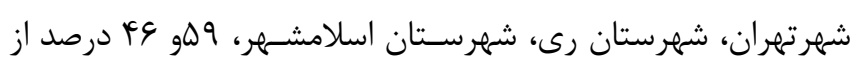

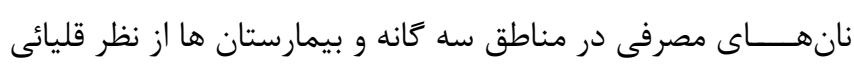

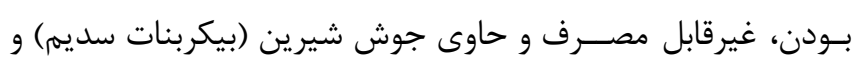

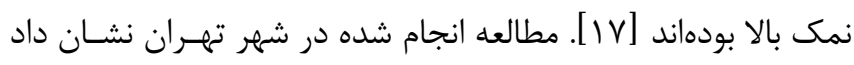

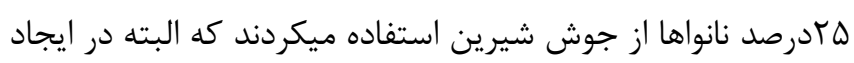

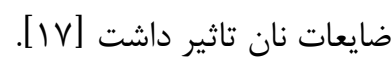

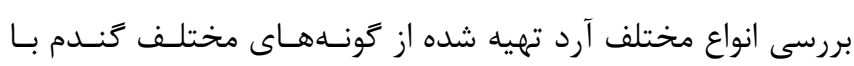

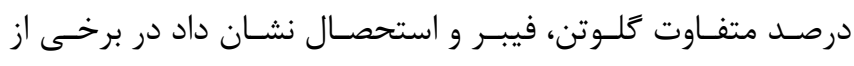

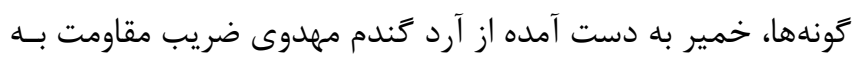

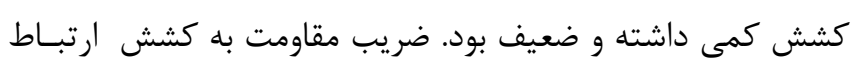

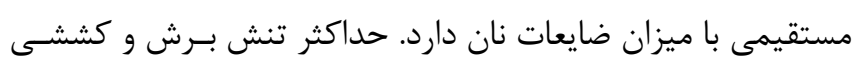

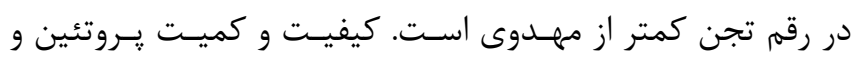

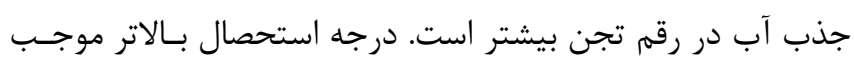

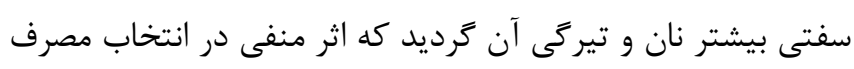

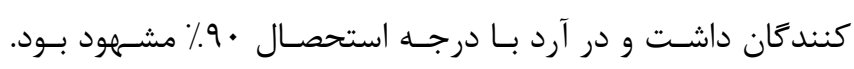

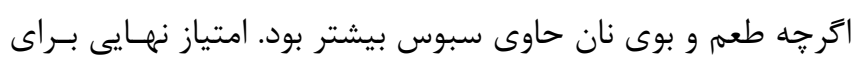

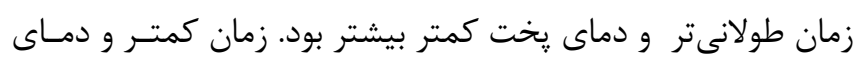

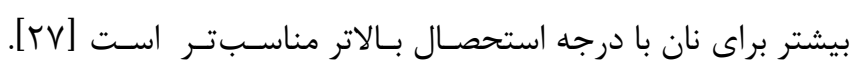

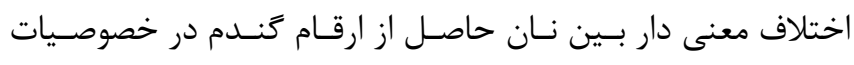

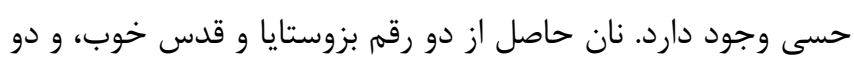

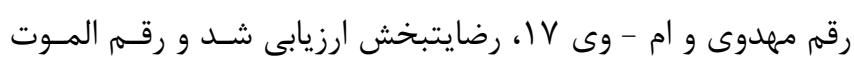

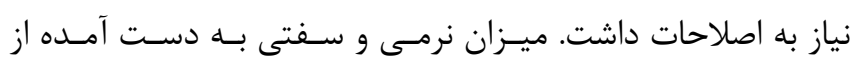

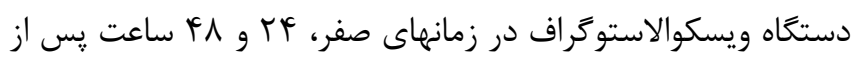

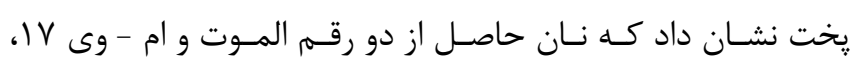

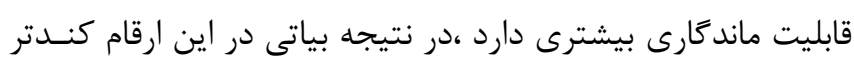

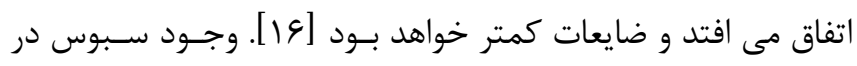

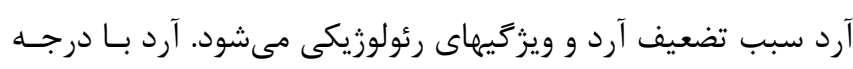


نان مصرفى مىتوان كَت بيشترين ضايعات مربوط به نانهاى لـواش

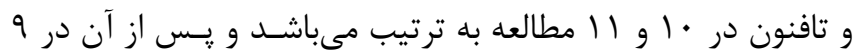

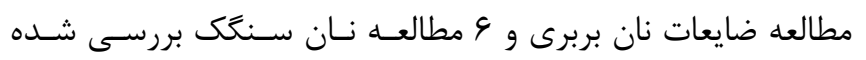
است.تنها در r مطالعه نان سنتى محلى بررسى كرديد. جزئيـات در

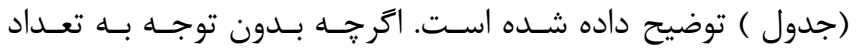

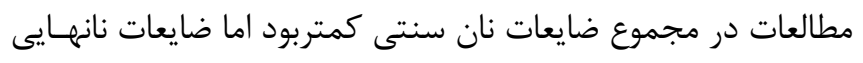

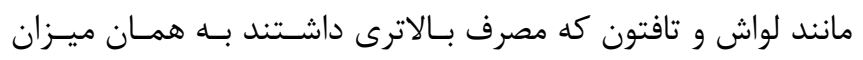

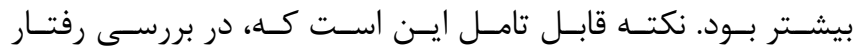

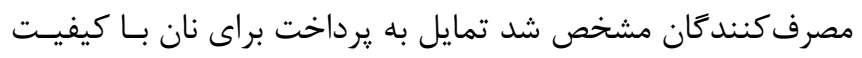

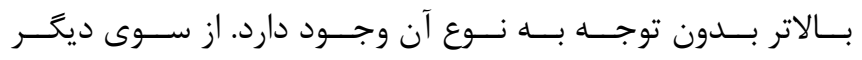

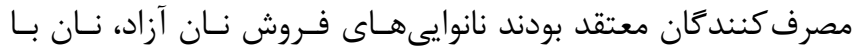

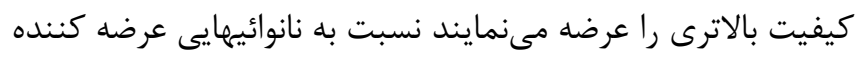

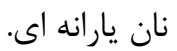

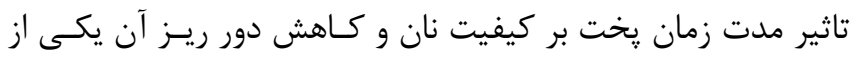

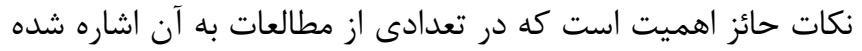

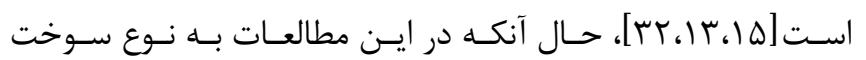

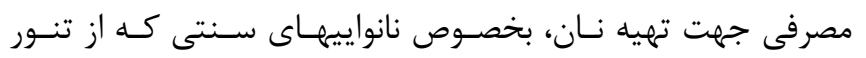
استفاده مى كنند اشاره اى نشده است .مطالعات متعددى در ايران و

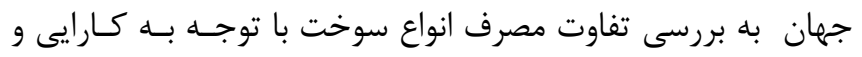

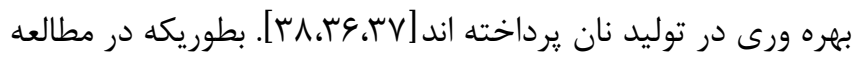

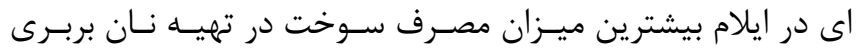

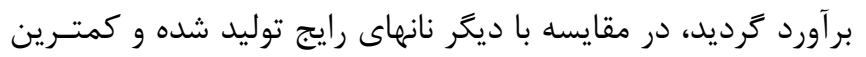

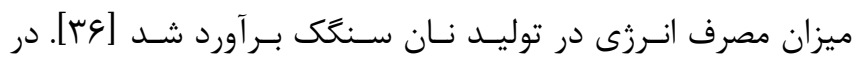

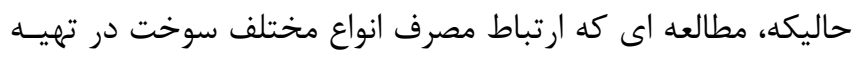

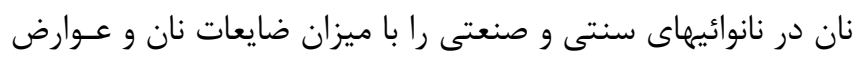

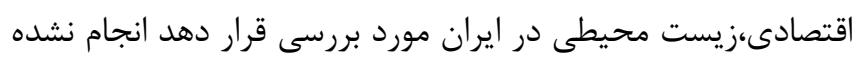

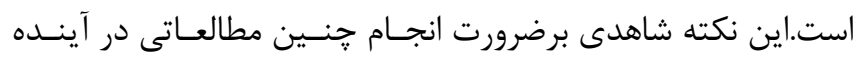

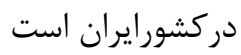

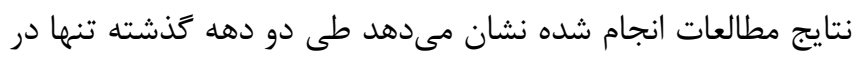

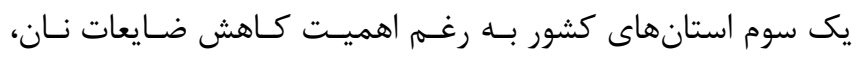

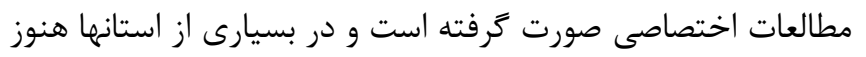

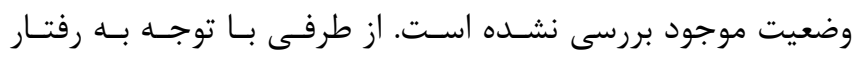

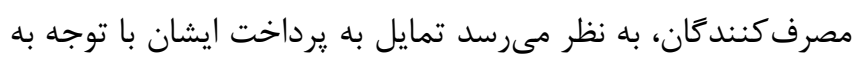

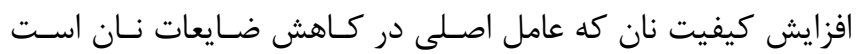

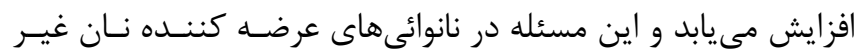

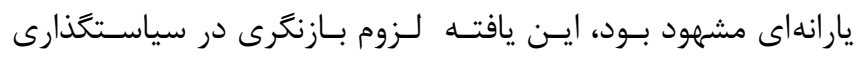

سياستخذارى در سطح كلان در كشور ايران دارد، بلكه مى تواند بــهـ

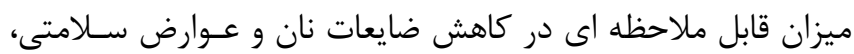
زيست محيطى و اقتصادى موثر واقع شود.

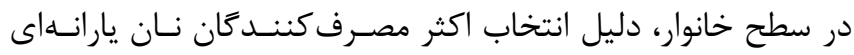

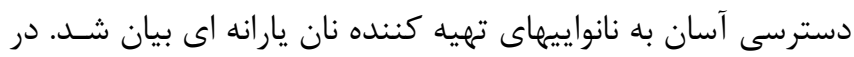

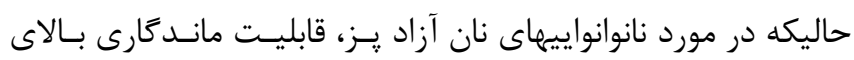

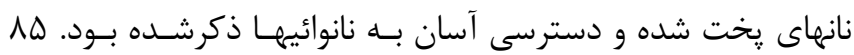

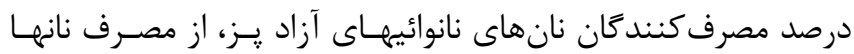

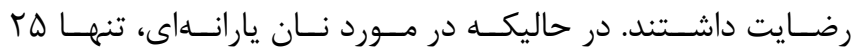

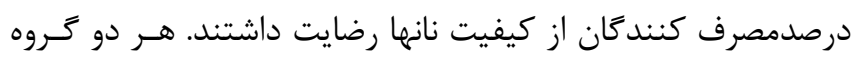

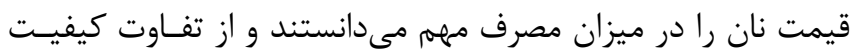

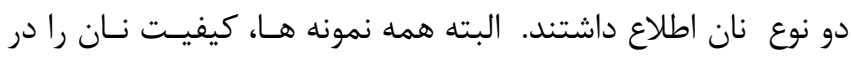

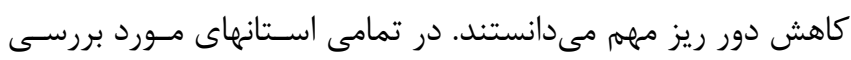

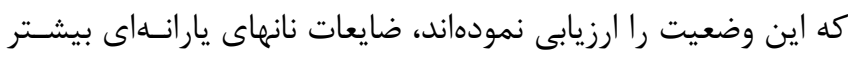

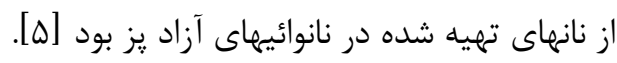

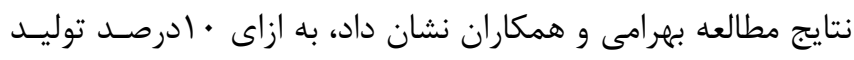

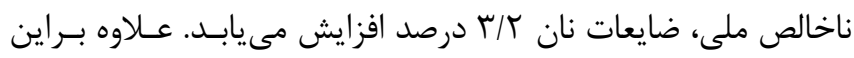

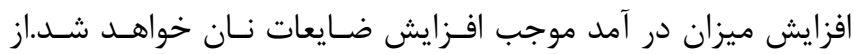

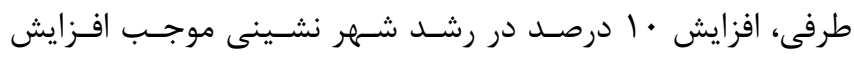

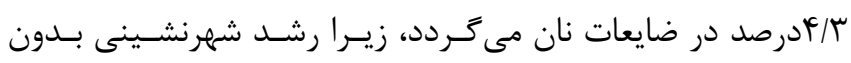

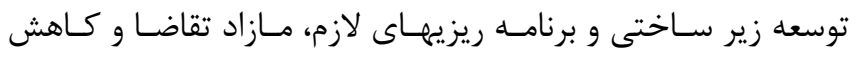

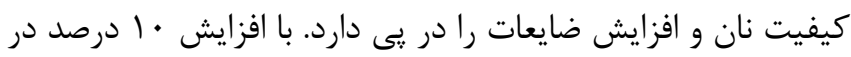

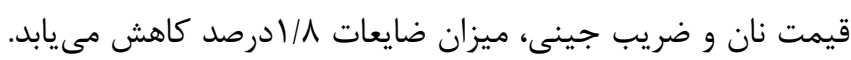

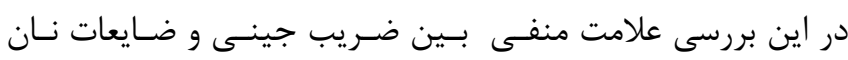

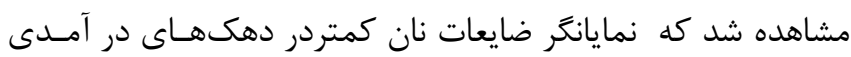

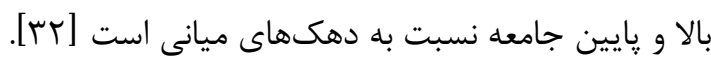

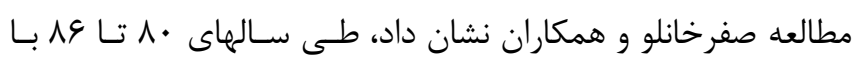

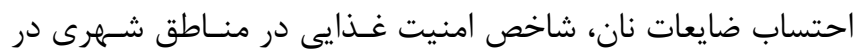

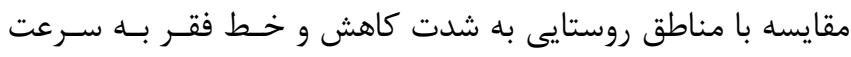

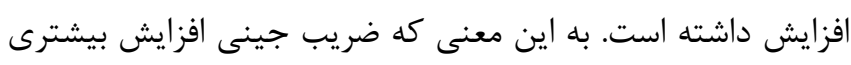

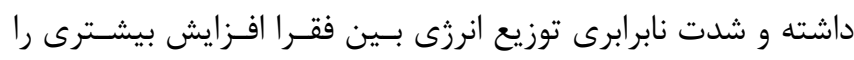

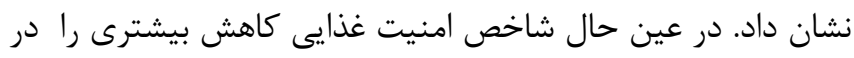

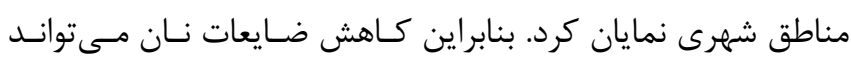

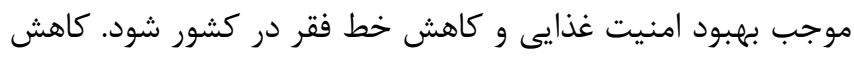

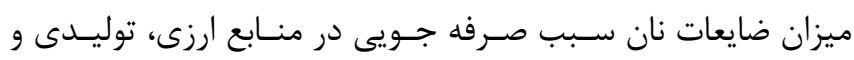

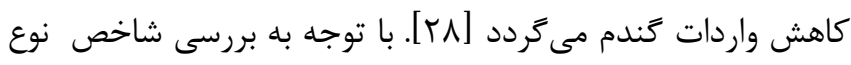


شواهد مفيدى براى محققان علاقمنـد بـهـ مطالعـه در ايـن حــوزه و كاهش عوارض اقتصادى، سلامتى ناشى از ضايعات نان ارائه نمايد.

\section{سهم نويسند}

رامـش عـالى يــور: طراحسى اوليـهـ مطالعـه، جسـتجو در يايخـاههــاى

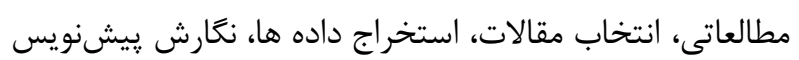
على كيانىراد: انتخاب مقالات، تدوين بحث، اصلاح نسخه نهايى

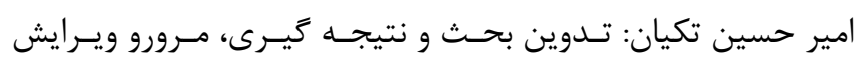
نهايى حامد يورآرام: طراحى اوليه مطالعه، تدوين بحث و ويرايش نهايى

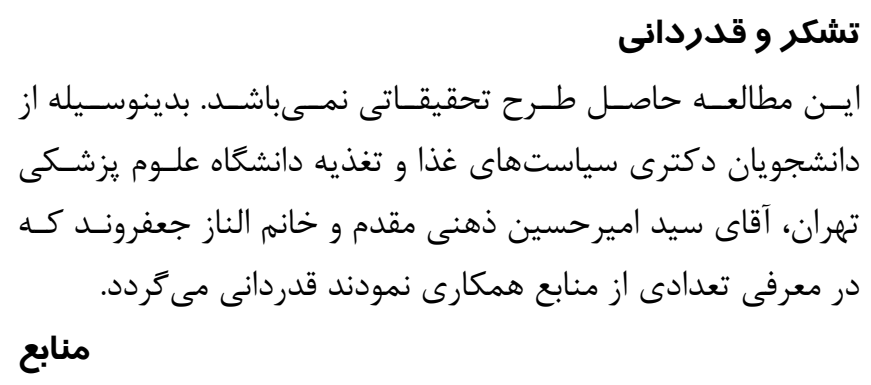

1. Collar C, Role of bread on nutrition and health worldwide. In: Rosell C M, Bajerska J, El Sheikha A. F. Bread and its Fortification for Nutritional and Healthy Benefits. 1st Edition. CRC Press/Taylor and Francis Group. Boca Raton(Florida) United State of America 2015:26-52

2. Gül A, Isik H, Bal T, Ozer S. Bread consumption and waste of households in urban area of Adana province. Electronic Journal of Polish Agricultural Universities 2003; 6:10

3. Djazayery A, Pajooyan J. Food consumption patterns and nutritional problems in the Islamic Republic of Iran. Nutrition and Health 2000; 14:53-61

4. Karizaki VM, Ethnic and traditional Iranian breads: different types, and historical and cultural aspects. Journal of Ethnic Foods 2017; 4:8-14

5. Saadat R, Azim Z, Hadi D. Assessment the population satisfaction of private bakeries compares to subsidial bakeries. Quart Journal Economical Modeling 2008; 5:48-70

6. Shahnoshi N, Jalerajabi M, Firoozzaree A. Gaphari A. Applying Disciminant Analysis and D. Abased ArtificialL NeuralL Network to Invetigate Discriminators of High and Middle Waste Bakers and Forecasting Their Categories (Case of Mashhad). Agricultural Economics 2013; 7:101-32[in Persian]
تخصيص يارانـهـ بــه كَنـدم، آردو انجـام مطالعـات بيشـتر را يـاد آور

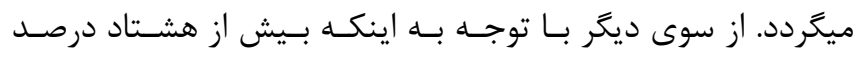

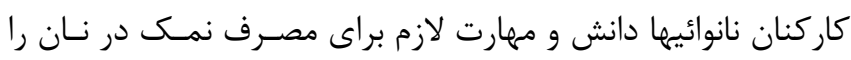

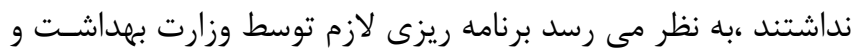

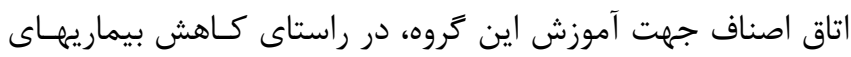

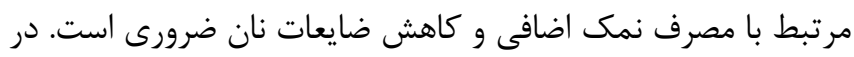

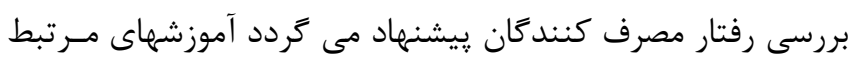

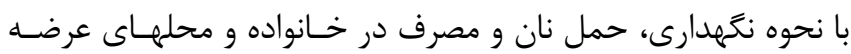

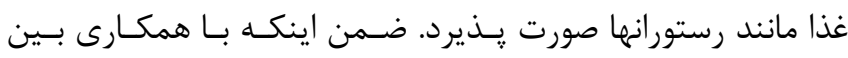

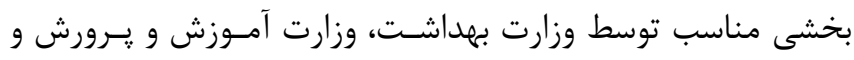

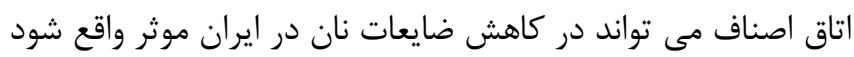

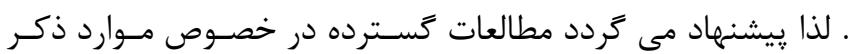

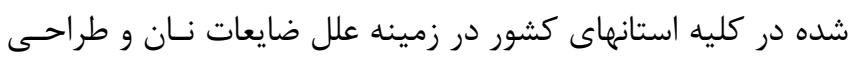

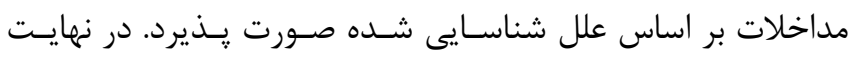

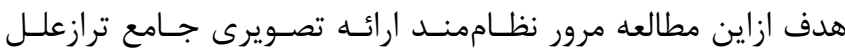

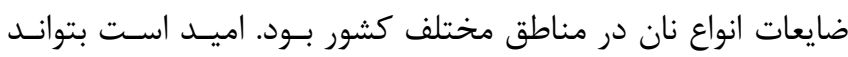

7. Hagh Nazari S, Zaringhalami S. Qualitative features of yeast used in Zanjan's bakeries. Journal of Food Science and Technology 2016; 13:31-45 [in Persian]

8. Abdollahzadeh A. Investigation the Effecttive Factors on Bread Waste in Sabsevar County. Journal of Food Science and Technology 2017; 9:89-97 [in Persian]

9. Nafiseh M, Shahedi Mohammad, Gholamhossein K. Study the Optimum Methods of TAFTON Bread Packaging Journal of Water and Soil Science 2004; 8:157-70[in Persian]

10. D'Elia L, Rossi G, Ippolito R, Cappuccio FP, Strazzullo P. Habitual salt intake and risk of gastric cancer: a meta-analysis of prospective studies. Clinical Nutrition 2012; 31:489-98

11. Loloei S, Pouraram H, Majdzadeh R, Takian A, Goshtaei M, Djazayery A. Policy analysis of salt reduction in bread in Iran. AIMS Public Health 2019; 6:534

12. Nasehi B, Azizi Tabrizzad $M \quad H$, Hadian $Z$. Different Approaches for Determination of Bread Staling. Iranian Journal of Food Science and Technology 2009; 6:53 -63[in Persian]

13. Salehifar M, Seyedein Ardebili S.M, Azizi M. Effects of Variation in Flour Extraction Rate on Dough Rheology, Staling and Retrogradation of 
Lavash Breads. Journal of Food Technology and Nutrition 2010; 7:17-28[in Persian]

14. Alibeygi A.H, Geravandi SH, Athari Z. Methods to Reduce Bread Waste Among Houswives in Kermanshah. Journal of Woman and Society 2012; 2:73-91[in Persian]

15. Ghanbari M, Shahedi. M. The Effect of Baking Time and Temperature on TAFTOON Bread Staling. Journal of Science and Technology of Agriculture and Natural Resources 2008; 12:327 - 33[in Persian]

16. Bideli N. Study on the Baking Valu and Stailing of Flat- Bread Produced from Five Varieties of Wheat in Khorasan Provinc. Journal of Agricultural Engineering Research 2004; 5:9-36[in Persian]

17. Aryaeian N, Soltan Dallal M. M, Dastbse Mojarrad A, Kaffashi T, Pirhadi E, Zeraati H, et al. Evaluation of Consumed Bread in Hospitals Affiliated to Tehran University of Medical Sciences. Payesh 2012; 11:2718 [in Persian]

18. Jalerajab M, Firoozzarea A, Shahnoshi N, editors. Estimation of Capita Bread Waste Function for Correction Current Bread Consumption Pattern (Case study: Mashhad City). The 8th Biennial Conference of Iranian Agricultural Economics Society 2012; Shiraz. https://www.shahnoushi.ir/[ in Persian]

19. Jalerajabi $M$, Shahnoshi $N$, Daneshvar $M$, Firoozzare A, Dehghanyan S, Razavi S. M. A. Modeling and Prediction of Bread Waste Using Time Series Models and Artificial Neural Neyworks (ANN). Iranian Journal of Agricutural Economics and Development 2011; 42:163-73[in Persian]

20. Akbari N, Khoshakhlagh R, Sameti M, Shahidi A. Estimation of Consumers' Willingness to Pay for Increasing Bread Quality in 2007. (Case study: Isfahan City). Journal of Kerman University of Medical Sciences 2010; 3:89-113[in Persian]

21. Rahimzadeh H, Mansourian M, Kargar M, Qorbani M, Bayrami S, Shafiian Z. Knowledge, Attitude and Practice of Bakeries in of GORGAN about the Use of Sodium Bicarbonate in Bread. Payesh 2012; 11:27983[in Persian]

22. Safarkhanlo A, Mohammadinejad A. Review of the Effects of Bread Wastes on Poverty Line and Food Security Index of the Rural and Urban Household of Iran During 2001- 2007 Journal of Agricultural Economics \& Development 2018; 19:53-78[in Persian]

23. Omidvar N, Aminpour A, Ghavamsadri M, Kavian F, Rokni S. Knowledge, Attitude, and Practice of Bakers Regarding Different Aspects of Bread
Production in the City of Tehran. Iranian Journal of Nutrition Sciences and Food Technology 2007; 2:2736[in Persian]

24. Alibeygi AH. Attitude of Wheat Producers, Bakers, and Consumers Toward Factors Influencing Bread Losses. Iranian Journal of Agricultural Economics and Development Research 2008; 39:4553[in Persian]

25. Azhdari S, Mortazavi S. A, Moosavi S. H. A, Vakilpour MH. Investigation the Bread Waste Reduction on the Iranian's Consumer's Welfare. Agricultural Economics and Development 2013; 21:69-89[in Persian]

26. Gholami Parizad E, Khosrvi A, Pourabas A, Mahdizadeh MA. A Study on the Effective Factors of Bread Wastes in Ilam Urban Bakeries (2006-7). Journal of Ilam University of Medical Sciences 2009; 16:8-17[in Persian]

27. Sadat Rasoul S. M, Nateghi L, Shahab Lavasani A, Seyed HE. The Effect of Its Dough Contains Lactobacilli Paracase and Fermentum on The Physicochemical Properties and Shelf Life of Barbarian Bread. Journal of Food Science and Technology 2019; 11:1-14 [in Persian]

28. Naghipour F, Sahraiyan S, Ghiafeh Davoodi M, Karimi M, Sheikholeslami Z. The Effect of Primary, Middle and Final Fermentation Time on Quantitative and Qualitative Properties of Barbari Bread Journal of Food Science and Technology 2013; 10:47 -55 [inPersian]

29. Salehifar M, Seyedin Ardebili S. M, Azizi M. The Effects of Bran Particles Variations of Flour on Quality, Gelatinization and Retrogradation of Iranian Flat Breads Journal of Food Science and Technology 2011; 8:1-14[in Persian]

30. Alami A, Banoorkar S, Rostamiyan T, Asadzadeh Seyedeh N, Morteza MM. Quality Assessment of Traditional Breads in Gonabad Bakeries, Iran. Journal of Research and Health 2015; 4:835-41[in Persian]

31. Ebrahimzadeh A, Mohammadzadeh F, Salimi A. Prevalence of Fungal Contamination of Flours in Zahedan Bakeries in 2013 Medical Journal of Mashhad University of Medical Sciences 2014;57:705-10 [in Persian]

32. Bahrami S, Shahedi M. The Effect of Wheat Cultivar, Flour Extraction Rate, and Baking Duration and Temperature on Dough Rheological Properties, Bread Staling, and Organoleptic Properties. Water and Soil Science (Journal of Science and Technology of 
Agriculture and Natural Resources) 2004; 8:195-203 [in Persian]

33. Dewettinck K, Van Bockstaele F, Kühne B, Van de Walle D, Courtens T, Gellynck X. Nutritional value of bread: Influence of processing, food interaction and consumer perception. Journal of Cereal Science 2008; 48:243-57

34. Jensen S, Oestdal H, Thybo AK. Sensory profiling of changes in wheat and whole wheat bread during a prolonged period of storage. Journal of Sensory Studies 2010; 25:231-45

35. Talaei M, Mohammadifard N, Khaje M-R, Sarrafzadegan N, Sajjadi F, Alikhasi H, et al. Healthy bread initiative: Methods, Findings, and Theories-
Isfahan Healthy Heart Program. Journal of health, Population, and Nutrition 2013; 31:49

36. Kheiralipour K, Sheikhi N. Material and energy flow in different bread baking types. Environment, Development and Sustainability 2021; 23:10512-27

37. Boyd GA, Guo YF. Development of ENERGY STAR ${ }^{\circledR}$ Energy Performance Indicators for Pulp, Paper, and Paperboard Mills. EPA Energy Star Technical Document 2012; 3:412-420

38. Le-bail A, Dessev T, Jury V, Zuniga R, Park T, Pitroff M. Energy demand for selected bread making processes: Conventional versus part baked frozen technologies. Journal of Food Engineering 2010 1; 96:510-9 